University of Redlands

\title{
The Partnership for Quality Medical Donations (PQMD) Online Mapping System
}

A Major Individual Project submitted in partial satisfaction of the requirements for the degree of Master of Science in Geographic Information Systems

\author{
by \\ Andrew Thomas Haglund \\ Committee in Charge: \\ James Ciarrocca M.S., Chair \\ Bryan D. Baker, Ph.D.
}

June 2008 
The Partnership for Quality Medical Donations (PQMD)

Online Mapping System

Copyright @ 2008

by

Andrew Thomas Haglund 
The report of Andrew Thomas Haglund is approved:
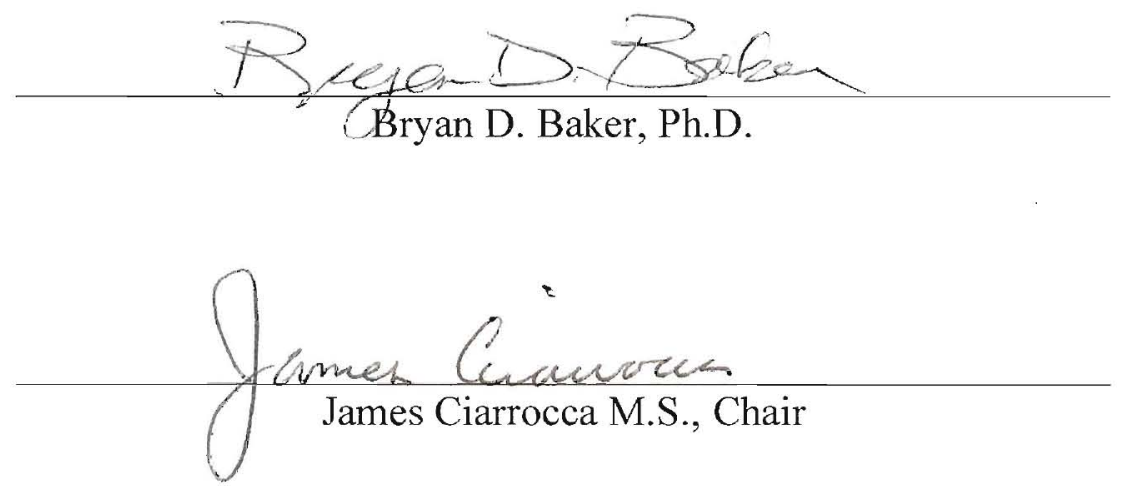

June 2008 



\section{ACKNOWLEDGEMENTS}

I would like to start by thanking my wife, Laurel, and my sons Reed, Joshua, and Ethan, for their support through the entirety of the U of R MS GIS program and most especially this project. You guys have made great sacrifices for me; without your love and support I could not have done any of this.

I would like to thank my advisor Jim Ciarrocca, your support and understanding of my unique part-time status with the program has been appreciated greatly. Jim, I was so impressed by your openness with me at the onset of our advisee/advisor relationship, with respect to your status within the academic GIS community and how that might effect my academic future. You've modeled integrity and honesty that will stick with me as I now start my academic career and the advising of my own students.

I would also like to thank Bryan Baker for your willingness to serve on my committee and for all of the technical assistance you provided me as I built this system.

I am most grateful to and would like to thank the faculty and staff of the U of R MS GIS program. Special thanks to Theresa Ellis, Program Coordinator, for putting up with me and my part-time status and the unique situations that it got us into. Theresa, you went the extra mile for me so many times and I really do appreciate it. There is nobody who will truly be able to fill your shoes when you're gone!

Many thanks to my client Seth Wiafe of Loma Linda University Health Geoinformatics and The PQMD, you provided a great project and wonderful support during the development of this system.

Thanks to my classmates of cohort 11 and 11.5! 



\begin{abstract}
The Partnership for Quality Medical Donations (PQMD) Online Mapping System

by

Andrew Thomas Haglund

In countries where medical consumables, pharmaceuticals, and other medical supplies are difficult to acquire, donations become the major means of obtaining these goods. The Partnership for Quality Medical Donations (PQMD) is an alliance of humanitarian aid organizations, pharmaceutical companies, and medical products manufacturers that combine to donate medical products to underserved nations and disaster victims around the globe. Prior to this project the PQMD has not had the ability to track and analyze their global donations. Therefore, it was assumed that some geographic areas were poorly covered while others experienced duplicate donations. This project developed an ArcGIS Server based web mapping application that enables the integration, analysis, and visualization of available annual PQMD donation data, with the hope of improving the overall donation performance of the PQMD member organizations. The web mapping application allows users to query the PQMD annual donation data by member, by country, and by year in order to locate both underserved areas as well as areas of duplicated donations. The system helps to identify unmet needs, improve resource management, and increases communication within the PQMD and its member
\end{abstract} organizations. 



\section{Table of Contents}

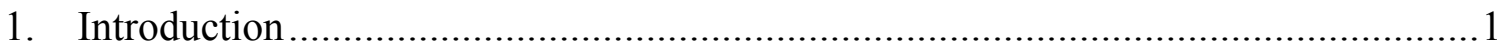

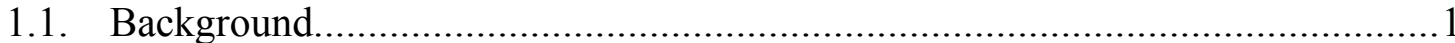

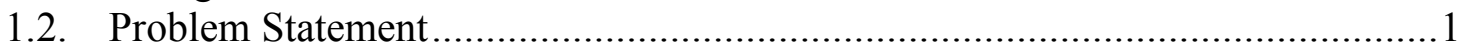

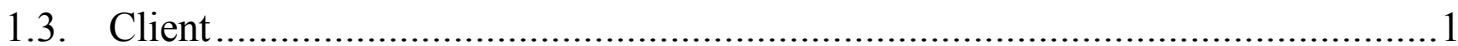

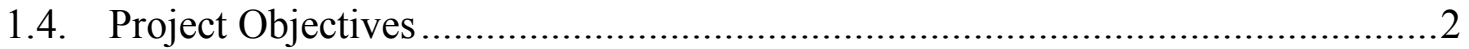

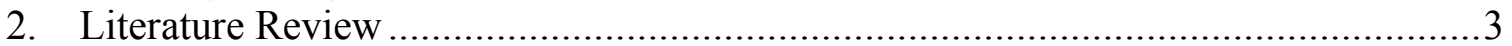

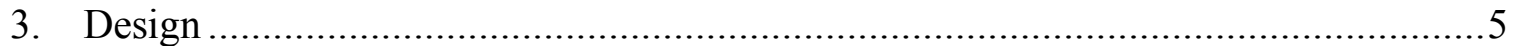

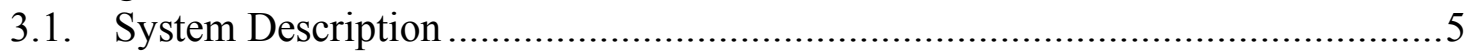

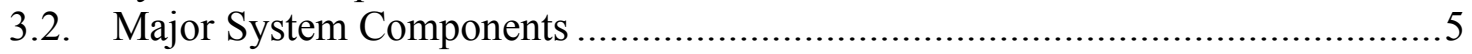

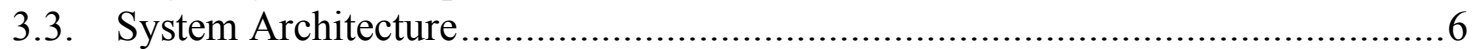

3.4. System Requirements \& Exclusions ............................................................

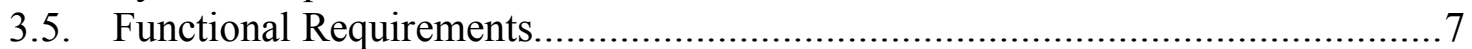

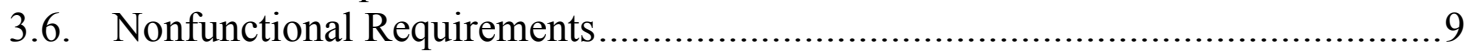

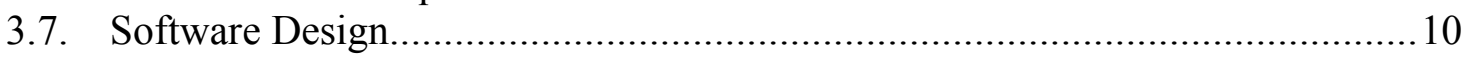

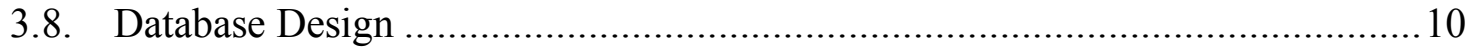

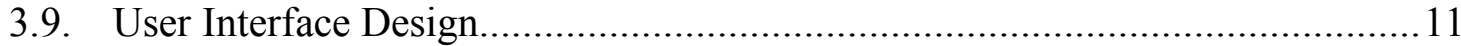

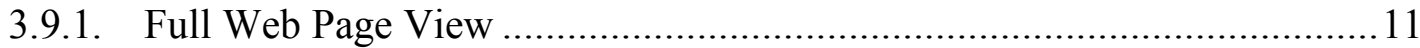

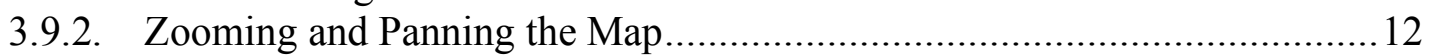

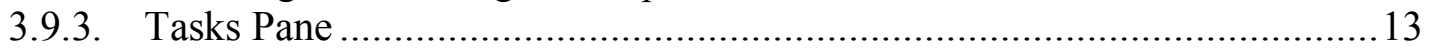

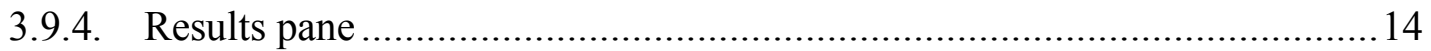

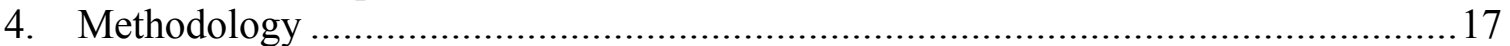

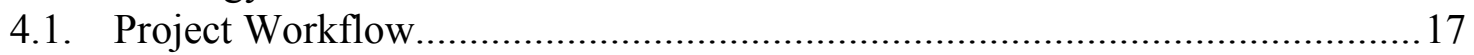

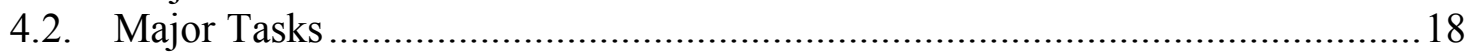

4.2.1. PHASE I - System Analysis and Requirements ........................................18

4.2.2. PHASE II - Data \& Map Preparation........................................................ 18

4.2.3. PHASE III - Web Application Creation, Customization, and Testing .........19

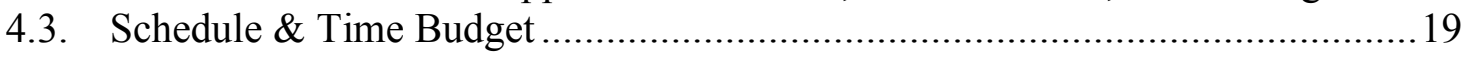

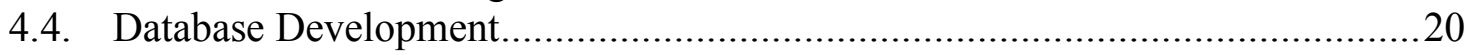

4.4.1. Donations200X Feature Classes ………….............................................. 21

4.4.2. Countries Feature Class ........................................................................2

4.4.3. Base Map Feature Classes - WORLD30 \& Continents...............................24

4.4.4. Client requested non-project point feature classes....................................25

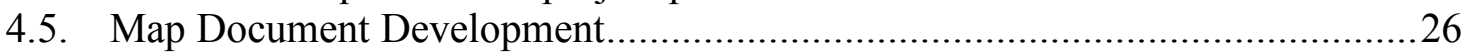

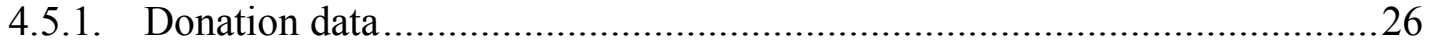

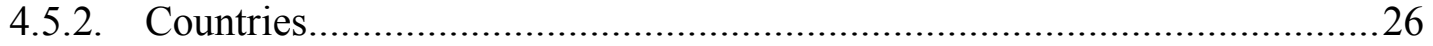

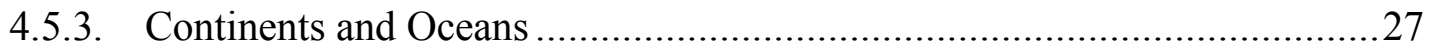

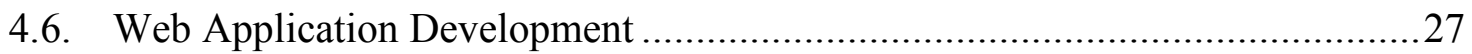

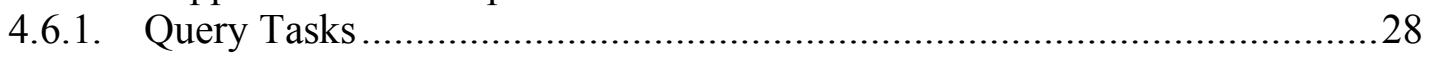

4.6.2. Custom Results Container (ZoomToResults) ..........................................28

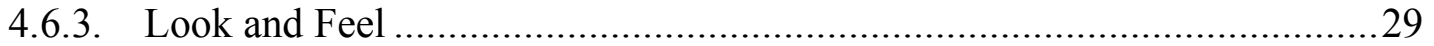

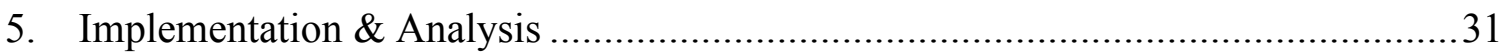

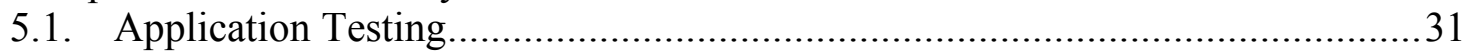

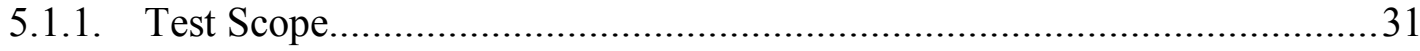

5.1.2. Test Environment \& Schedule ................................................................... 31 


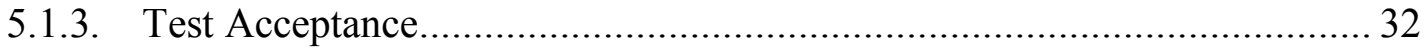

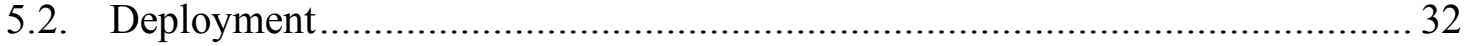

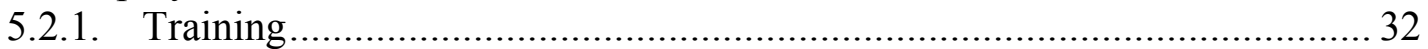

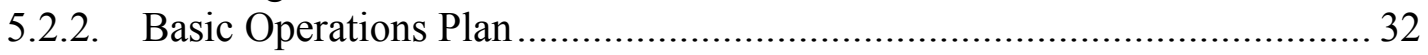

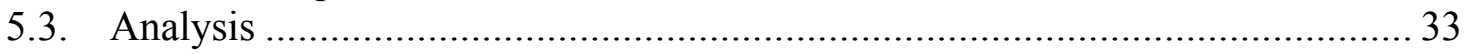

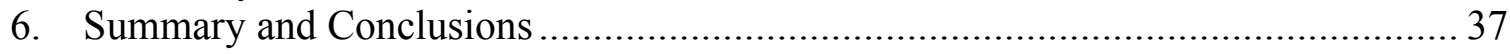

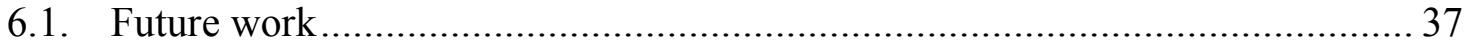

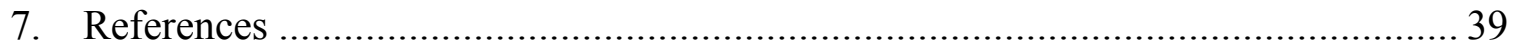

Appendix A - Complete Geodatabase Diagram...................................................... 41

Appendix B - Complete System via ArcCatalog ............................................... 43 


\section{Table of Figures}

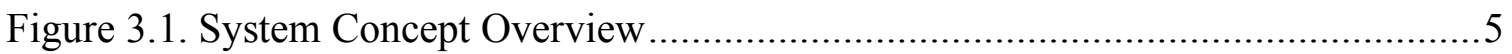

Figure 3.2. System Architecture.............................................................................6

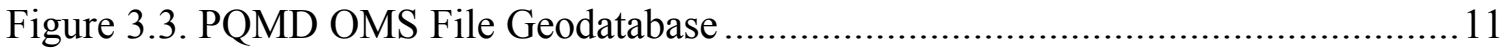

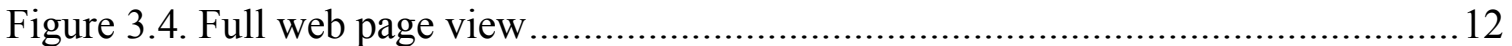

Figure 3.5. Zoomed map view with country labels shown..........................................13

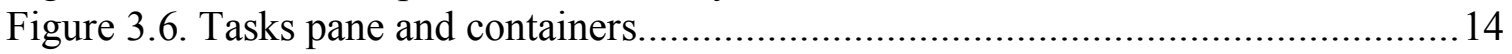

Figure 3.7. Results pane (3 levels of results displayed) .............................................. 15

Figure 4.1. Project workflow diagram...................................................................... 17

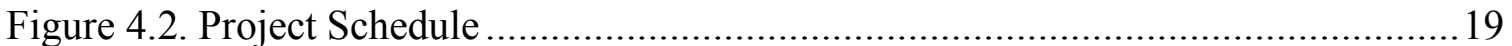

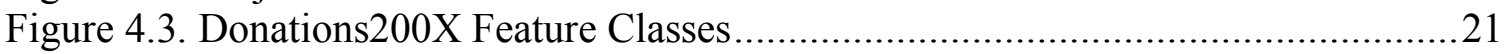

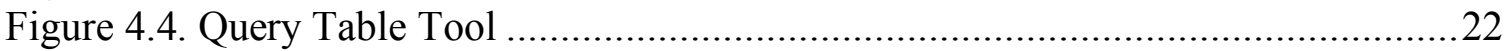

Figure 4.5. Countries and Base Map Feature Classes ................................................2.

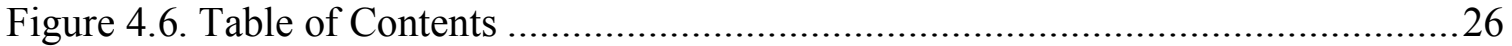

Figure 4.7. Map showing GDP, Continents, and Oceans .............................................27

Appendix Figure 1. PQMD OMS Geodatabase Diagram ..........................................41

Appendix Figure 2. PQMD OMS System Files..........................................................43

\section{List of Tables}

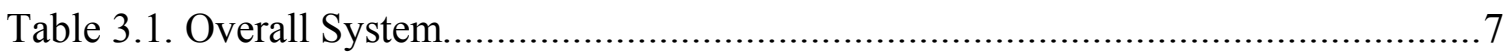

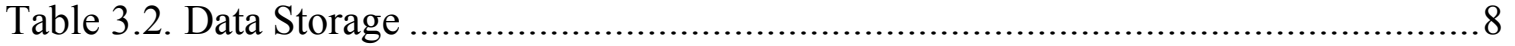

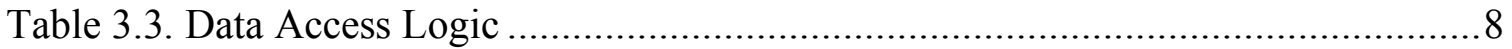

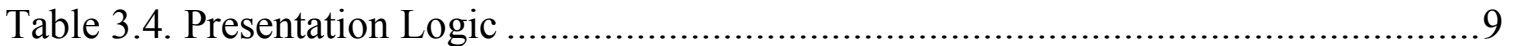

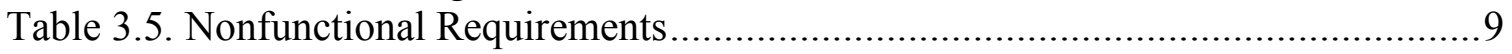

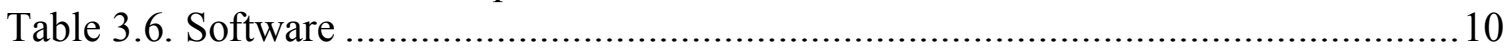

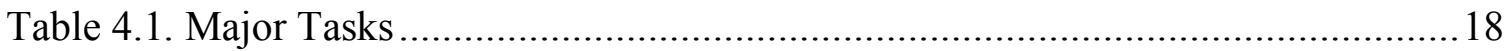

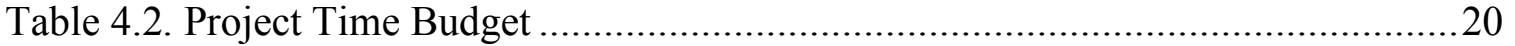

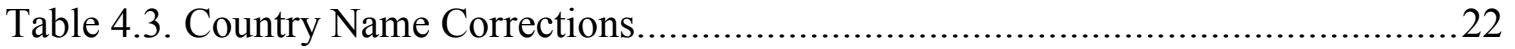

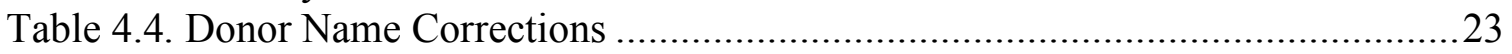




\section{List of Acronyms}

$\begin{array}{ll}\text { ADF } & \text { Application Development Framework } \\ \text { ESRI } & \text { Environmental Systems Research Institute } \\ \text { GDB } & \text { Geodatabase } \\ \text { GDP } & \text { Gross Domestic Product } \\ \text { GIS } & \text { Geographic Information System } \\ \text { LLU } & \text { Loma Linda University } \\ \text { MDB } & \text { Microsoft Access database } \\ \text { MIP } & \text { Major Individual Project } \\ \text { MS GIS } & \text { Masters of Science, Geographic Information Systems } \\ \text { MXD } & \text { ArcGIS Map Document } \\ \text { NGO } & \text { Non-Government Organization } \\ \text { PQMD } & \text { Partnership for Quality Medical Donations } \\ \text { PQMD OMS } & \text { Partnership for Quality Medical Donations Online Mapping System } \\ \text { U of R } & \text { University of Redlands } \\ \text { WHO } & \text { World Health Organization }\end{array}$





\section{Introduction}

This document outlines the development of an interactive online mapping application designed to track and analyze the medical product donations of the Partnership for Quality Medical Donations (PQMD). The completed application is a readily accessible, easily updated, scalable, and user-friendly Internet application. The system provides a mechanism that enables the PQMD to better communicate donation data to its members, resulting in more effective distribution of donations worldwide. This project is a Major Individual Project (MIP) of the Master of Science in Geographic Information Systems program (MS GIS) at the University of Redlands, California.

\subsection{Background}

In countries where pharmaceutical products, medical equipment, and other medical supplies are difficult to acquire on a consistent basis, medical product donations are the major source of these critical commodities. The PQMD is a private humanitarian nonprofit association recognized by the World Health Organization (WHO) and other non-government organizations (NGOs) as one of the leading authorities in quality medical donations. The PQMD estimates that medical product donations account for more than half of all medical supplies in these locales. Even in developed countries with relatively good access to medical supplies, medical donations are needed in special circumstances such as natural disaster response (e.g., Hurricane Katrina of 2005 in the United States). Although they are a leader in this industry, the PQMD, prior to this project, has not had the ability to track and analyze their combined global donations.

\subsection{Problem Statement}

Each PQMD member organization is responsible for the coordination and management of product distribution. There is little to no integration or sharing of data between PQMD member organizations regarding the medical product donations they are making. Communication is quite limited even between those members that operate in the same geographic area. Often this results in areas poorly covered by product donations, or duplication of efforts. Such disparities make it difficult to target populations who are in desperate need of medical products, and without an effective inter-organization communication tool, member organizations cannot accurately assess the donation needs of the communities they serve. This project uses a web mapping application to integrate annual donation data in an effort to improve the overall donation performance of the PQMD and its partners.

\subsection{Client}

The Partnership for Quality Medical Donations is an alliance of 29 health care manufacturers, pharmaceutical companies, and non-governmental organizations. The PQMD works with the WHO, the World Bank, and other related NGOs to improve the effectiveness and efficiency of medical product donations. The PQMD is dedicated to the development, dissemination and adherence to high standards in the delivery of medical products to under-served people and disaster victims around the world. The PQMD 
recently announced that medical product donations have more than doubled from $\$ 1.4$ billion in 2003 to an average of \$3 billion per year in both 2004 and 2005. Since its incorporation in 1999, the PQMD has been dedicated to raising the standards for medical products by donating and delivering appropriate pharmaceuticals, medical equipment, and other supplies as well as leading out several single disease initiatives to countries in need. Currently, PQMD member organizations operate in more than 170 countries around the world. The PQMD is highly committed to, and excited about the success of this project. The PQMD provided their annual donation data for 2004, 2005, and 2006 to be included in this project. The primary client contact for this project was Seth Wiafe, MPH. Seth serves as a PQMD Board Member and is the Academic Director of the Health Geoinformatics Program at Loma Linda University School of Public Health, California.

\subsection{Project Objectives}

During an initial project-planning meeting with Seth Wiafe, PQMD board member, the following client-focused, project objectives were identified:

- Identify unmet medical product needs. Assist the PQMD members in deciding where to donate products by identifying underserved geographic areas.

- Improve resource management. The PQMD should be able to visualize its global presence, allowing its partners to more effectively leverage their resources.

- Provide a common donation program understanding. The system will facilitate the communication of the combined PQMD donations for all members to view and use in their donation planning. 


\section{Literature Review}

The literature review for this project focuses on three distinct themes: 1) the domain of public health and how it relates to geographic information systems (GIS); 2) Internet GIS and web mapping applications; and 3) web site usability. Although each of these are unique, it is not uncommon to find them discussed together and somewhat dependent on each other (in the literature). More specifically, the success of many GIS projects within the domain of public health seems to be dependant on the quality and usability of the web mapping applications, upon which they are built.

The PQMD is an organization focused on improving the donations of pharmaceuticals to underserved nations around the world (Nelson \& Prescott, 2003). The focus of the PQMD helps to frame this project within several larger domains, such as humanitarian aid, medical supplies and pharmaceuticals, and philanthropy. There are numerous articles asserting the benefits of the use of web mapping and Internet GIS as a tool to support and further international humanitarian aid (Benini, Conley, Shdeed, Spurway, \& Yarmoshuk, 2003; González-Casillas \& Pérez, 2005; Haeni, 2005; Kamadjeu \& Tolentino, 2006; Tanser \& Le Sueur, 2002; Theseira, 2002). Several articles cite more tactical applications such as landmine mapping and post disaster rapid-response planning tools (Benini et al., 2003; Tanser \& Le Sueur, 2002). Although these cases are quite different in purpose from the PQMD mapping project, some of the principles and tenants they are built on are quite applicable. For example, the need for international data standards and the willingness of all collaborators to share their data to support these web GIS initiatives is a theme that occurs repeatedly in the literature (Boulos \& Honda, 2006; González-Casillas \& Pérez, 2005). Another important and recurring theme is the value in having web GIS tools operational prior to a crisis, rather than having to scramble to collect data and build a system after or during an event (Hoppen, 2001; Maclachlan, Jerrett, Abernathy, Sears, \& Bunch, 2007).

The use of GIS within the medical products and pharmaceutical domains is generally focused on growing and managing sales territories. For example, Craddock (2007), discusses drug distributions in Sub Saharan Africa and how GIS can be used to track their use in politically challenging geographic regions. This, however, is at a much smaller scale than what the PQMD project will map. Similarly, the use of GIS within the philanthropic domain is largely focused on the analysis of where donor dollars are located or coming from, rather than where they are going to (Daniel, 2003).

The second theme of this project is Internet technology and web mapping. The literature is rich with information on best practices, examples, and comparisons of these technologies. Kamadjeu and Tolentino (2006) provide evidence that web GIS enables a much wider audience and promotes collaboration in ways not available using traditional desktop GIS software. There has been discussion and research around various server software technologies, such as open source vs. commercial packages, and which is easier to install, use, and maintain (Boulos \& Honda, 2006; Kamadjeu \& Tolentino, 2006). This hotly contested debate is often decided by a local system administrator's bias towards open or closed architecture. The literature is also very clear on the enhanced collaboration afforded by web GIS (Benini et al., 2003; González-Casillas \& Pérez, 2005; Haeni, 2005; Kamadjeu \& Tolentino, 2006; Tanser \& Le Sueur, 2002; Theseira, 2002). 
This is one of the primary objectives of this project: to enhance collaboration between PQMD member organizations.

The third theme of this project, web application usability, is critically important with any web project and will likely be a formidable challenge. Krug (2000), states it plainly: "People won't use your web site if they can't find their way around it." Some of the commercially available web mapping applications tend to be oriented to the GIS user and require a certain familiarity with conventions used in desktop GIS software (Anderson \& Moreno-Sanchez, 2003). Careful attention to web usability has been maintained during the development of this web mapping application. 


\section{Design}

This chapter discusses design specifics of the PQMD Online Mapping System (PQMD OMS) focusing largely on the questions of "what was done" and "what was required" to build the system. The chapter starts with a general overview of the system and its required components, followed by several sections on the expected functionality for the system, and then concludes with design descriptions of each of the system's major components.

\subsection{System Description}

The PQMD OMS is a web accessible GIS built using the Environmental Systems Research Institute's (ESRI) ArcGIS 9.2 desktop and server technologies. The system offers an interactive web application displaying a global map and a set of predefined queries of the PQMD annual donation datasets. Specific queries for Donations by Member and Donations per Country facilitate the visualization of combined PQMD member donation data. Figure 3.1 provides a graphical overview of the PQMD OMS. These queries assist PQMD management and members to better allocate resources to address unmet needs, while at the same time avoiding duplication of efforts or donations. An additional query of countries with less than $X$ number of $P Q M D$ members will further identify unmet needs, as countries with five or more PQMD members present have shown higher donation amounts (Wiafe, Haglund, \& Tong, 2007). The system provides a unified and highly accessible delivery mechanism for the available PQMD donation data to management and member organizations.

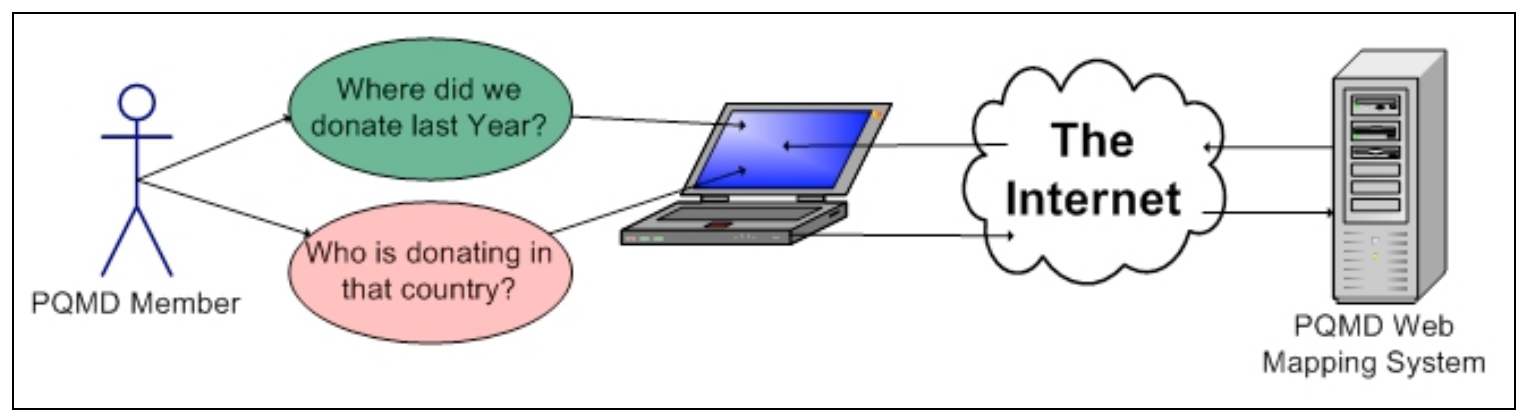

Figure 3.1. System Concept Overview

\subsection{Major System Components}

The PQMD OMS is comprised of four main system components. These components are:

- Raw PQMD annual donation data 2004, 2005, 2006 - delivered in .dbf format by year.

- Geodatabase - houses the data elements necessary for the project including PQMD donation data and all other base map layers.

- Map Document - Built using ArcGIS Desktop, includes all data layers present in the final web application. This is the foundation of the project. 
- ArcGIS Server - Physical system to serve the project out over the Internet using the following two logical systems:

- Web Service - enables the map document to be accessed via the web.

- Web Application - consumes the above web service and provides the framework for interactivity with the map document such as queries, zooming in and out, attribute identification, and feature selection.

\subsection{System Architecture}

The system architecture of the PQMD OMS can be divided into three main components: Data \& Map creation; Server \& Hosting; and End User Interface (see Figure 3.2).

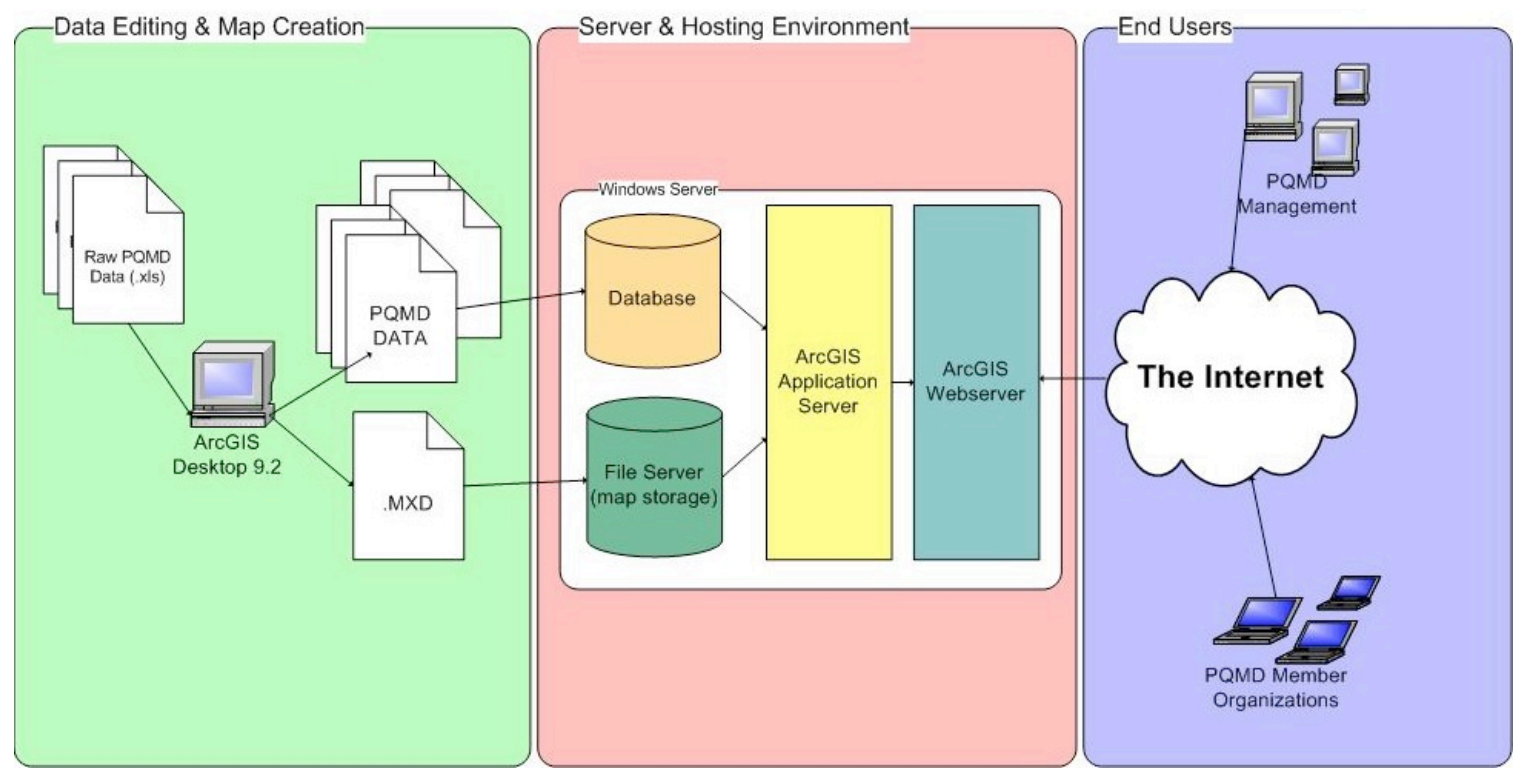

Figure 3.2. System Architecture

The first component, Data Editing and Map Creation, is where the PQMD donation data is converted for use within the GIS environment, accomplished using ESRI's ArcGIS Desktop 9.2. The base map, upon which the web application is based, is also created here. ArcGIS Desktop is also used to upload data (donation data, base map data, and map document .mxd) to the ArcGIS server and locate them within either the database or file system as appropriate.

The second component of the system is the physical Server and Hosting Environment. This component is where the lion's share of the work supporting the PQMD application is done. The server, running ArcGIS Server 9.2, provides file storage for the base map document, a geodatabase to store donation data and base map layer data, a web map service, a web application server to serve up the web map service, and a web server to host the web application to the Internet.

The final system component is the End Users web page, which provides the user interface for interacting with and querying the PQMD web mapping application. 


\subsection{System Requirements \& Exclusions}

The PQMD OMS requires a full use license of ArcGIS 9.2 Desktop and Server (Workgroup Standard), both of which the client provided for this project. The PQMD OMS project did not include the installation, configuration, or ongoing maintenance of the required Internet available (24/7/365) server running ArcGIS Server 9.2. At the inception of the project the client provided the necessary admin level access to the required systems to complete the solution. Management, maintenance and all future development of the PQMD OMS will be handed off to Loma Linda University Health Geoinformatics during the summer of 2008.

\subsection{Functional Requirements}

Tables 3.1 through 3.4 outline the various functional requirements for the PQMD OMS, as identified during the system analysis and design phase of the project. The functional requirements were divided into the following logical groups:

- Overall System

- Data Storage

- Data Access Logic

- Presentation Logic

Each table has one or more requirements in bold print, these are the most important within that logical group.

Table 3.1. Overall System

\begin{tabular}{|c|l|c|}
\hline REQ \# & Requirement & Priority \\
\hline FR3.1.1 & Internet browser based (cross browser/cross platform) & Mandatory \\
\hline FR3.1.2 & $\begin{array}{l}\text { Built using Web Services and Web Application } \\
\text { technologies (client requested ArcGIS Server 9.2) }\end{array}$ & Mandatory \\
\hline FR3.1.3 & $\begin{array}{l}\text { Displays PQMD Donation data (2004, 2005, 2006) on a } \\
\text { world map }\end{array}$ & Mandatory \\
\hline FR3.1.4 & $\begin{array}{l}\text { Web Map includes world countries displayed in a Robinson } \\
\text { projection }\end{array}$ & Mandatory \\
\hline FR3.1.5 & $\begin{array}{l}\text { World GDP (Gross Domestic Product) by country layer } \\
\text { available for display }\end{array}$ & Desirable \\
\hline FR3.1.6 & $\begin{array}{l}\text { Web Application color palate should match or compliment } \\
\text { PQMD's blue corporate color scheme (see www.pqmd.org) }\end{array}$ & Desirable \\
\hline FR3.1.7 & $\begin{array}{l}\text { Web application page should provide links to external web } \\
\text { pages e.g. PQMD.org, llugis.org, Redlands.edu }\end{array}$ & Optional \\
\hline FR3.1.8 & $\begin{array}{l}\text { Physically hosted from a secure sever located on The } \\
\text { Internet }\end{array}$ & Mandatory \\
\hline
\end{tabular}


Table 3.2. Data Storage

\begin{tabular}{|c|l|c|}
\hline REQ \# & Requirement & Mandatory \\
\hline FR3.2.1 & Data stored in a database & Desirable \\
\hline FR3.2.2 & $\begin{array}{l}\text { Data stored in an Enterprise class database (MS } \\
\text { SQL/Oracle) }\end{array}$ & Mandatory \\
\hline FR3.2.3 & $\begin{array}{l}\text { PQMD annual donation data should be stored in a way } \\
\text { such that it may be queried as individual years } \\
\text { donations. }\end{array}$ & $\begin{array}{l}\text { Database will store data layers for: world countries (w/GDP), } \\
\text { Contents }\end{array}$ \\
\hline FR3.2.4 & Database must be accessible to the web/application server & Mandatory \\
\hline
\end{tabular}

Table 3.3. Data Access Logic

\begin{tabular}{|c|l|c|}
\hline REQ \# & Requirement & Priority \\
\hline FR3.3.1 & $\begin{array}{l}\text { Query - “Donations by Member” for calendar years } \\
\text { 2004, 2005, 2006 }\end{array}$ & Mandatory \\
\hline FR3.3.2 & $\begin{array}{l}\text { Query - “Donations by Country” for calendar years } \\
2004,2005,2006\end{array}$ & Mandatory \\
\hline FR3.3.3 & $\begin{array}{l}\text { Query - “Countries with less than, more than, and equal } \\
\text { to } \underline{X} \text { number of members” }\end{array}$ & Mandatory \\
\hline
\end{tabular}


Table 3.4. Presentation Logic

\begin{tabular}{|c|c|c|}
\hline REQ \# & Requirement & Priority \\
\hline FR3.4.1 & $\begin{array}{l}\text { Queries should be grouped by calendar year within the } \\
\text { task pane of the web application e.g. The drop down } \\
\text { folder titled "Donations in } 2004 \text { " should include both } \\
\text { queries for the donations by member and by country for } \\
2004\end{array}$ & Mandatory \\
\hline FR3.4.2 & At full map extent all continents should be labeled & Mandatory \\
\hline FR3.4.3 & $\begin{array}{l}\text { Country labels should not be visible until zoom level is } \\
\text { inside of } 1: 50,000,000\end{array}$ & Mandatory \\
\hline FR3.4.4 & Pacific, Atlantic, and Indian oceans should be labeled & Desirable \\
\hline FR3.4.5 & $\begin{array}{l}\text { The Web Application page should contain the following map } \\
\text { tools and only these tools: Title Bar, Tool bar, Zoom In, } \\
\text { Zoom Out, Pan, Full Extent, Identify, Measure, Magnify, } \\
\text { Links, Tasks, Results, Map Contents, Map, Scale bar }\end{array}$ & Mandatory \\
\hline FR3.4.6 & $\begin{array}{l}\text { Results from task queries should display in both list } \\
\text { form as well as highlight the appropriate countries on } \\
\text { the map display }\end{array}$ & Desirable \\
\hline FR3.4.7 & $\begin{array}{l}\text { Query results should be able to be reset or cleared and the } \\
\text { map display should reflect this change and selections reset. }\end{array}$ & Mandatory \\
\hline FR3.4.8 & $\begin{array}{l}\text { The Map Contents (Layers) should be expanded for view } \\
\text { with all elements selected upon entry into the application. }\end{array}$ & Desirable \\
\hline FR3.4.9 & Map Contents (layers) may be toggled on or off by the user & Desirable \\
\hline FR3.4.10 & $\begin{array}{l}\text { PQMD donation data should be differentiated by year on } \\
\text { the map. }\end{array}$ & Mandatory \\
\hline
\end{tabular}

\subsection{Nonfunctional Requirements}

In addition to the functional requirements listed in Section 3.5, several characteristics or nonfunctional requirements were also identified during system analysis discussions with the client. The nonfunctional requirements for the project are listed in Table 3.5.

Table 3.5. Nonfunctional Requirements

\begin{tabular}{|c|l|c|}
\multicolumn{1}{c|}{ REQ \# } & Pequirement & Mandatory \\
\hline NFR3.5.1 & $\begin{array}{l}\text { User Friendly - System will be accessed by non-GIS users } \\
\text { and must be very easy to use. }\end{array}$ & Mandatory \\
\hline NFR3.5.2 & $24 / 7 / 365$ Availability & Mandatory \\
\hline NFR3.5.3 & Scaleable to accommodate future years donation data &
\end{tabular}




\subsection{Software Design}

The PQMD OMS is based on out-of-the-box ESRI and Microsoft technologies and did not require the use of custom or self-programmed applications. The PQMD application does, however, use extensive customization of the ArcGIS Server 9.2 web application environment. Table 3.6 outlines each of the software applications needed to complete the PQMD application and provides brief descriptions as to how they are used within the PQMD OMS application development and hosting process.

Table 3.6. Software

\begin{tabular}{|l|l|}
\hline \multicolumn{1}{|c|}{ Application } & \multicolumn{1}{c|}{ Purpose } \\
\hline ESRI ArcGIS Desktop 9.2 sp5 & Data Conversion - Query Table, Map Creation \\
\hline $\begin{array}{l}\text { ESRI ArcGIS Server Workgroup } \\
\text { Standard .NET 9.2 sp5 }\end{array}$ & Web Services \& Web Application Hosting \\
\hline Microsoft Server 2003 R2 & Server Operating System \\
\hline Microsoft Visual Studio.NET 2005 & $\begin{array}{l}\text { Development environment for customizing Web } \\
\text { Application }\end{array}$ \\
\hline ESRI File Geodatabase & Database \\
\hline
\end{tabular}

\subsection{Database Design}

The PQMD OMS is based on a spatial database format created by ESRI called the file geodatabase. This simple geodatabase containing just six feature classes is outlined in Figure 3.3. The six feature classes are: Cntry00 (countries), Continents, Donations2004, Donations2005, Donations2006, and WORLD30 (world background). Each of these feature classes and their attributes is discussed in detail in Section 4.4. The two point features shown within the geodatabase, Ghana finalxy and PQMDFacilitiesInventory, are datasets the client requested to be displayed in the web application but are not part of this project (Section 4.4.4 provides further explanation on the point features). 


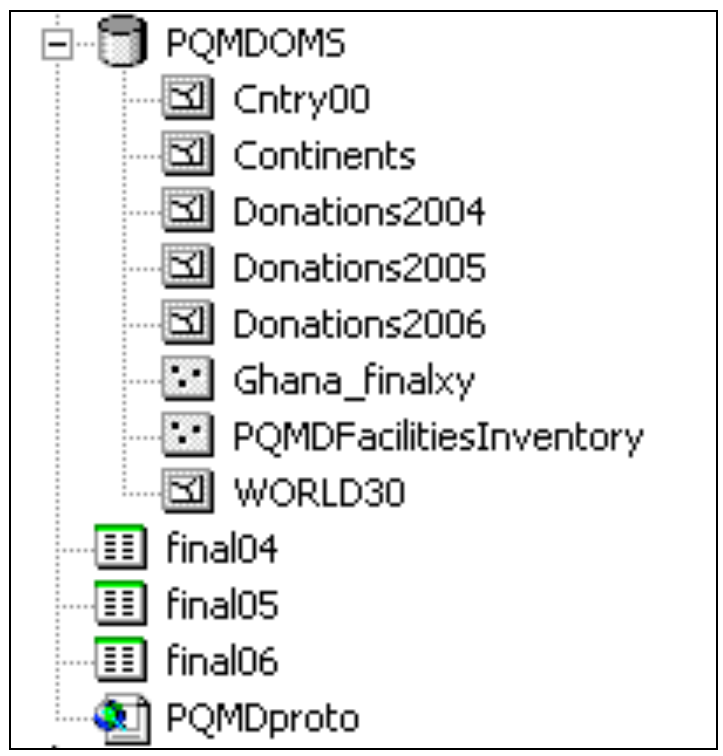

Figure 3.3. PQMD OMS File Geodatabase

\subsection{User Interface Design}

Usability is of the utmost importance to the success of the PQMD OMS. The PQMD OMS is web browser-based and is compatible with most modern web browsers. The ArcGIS Server 9.2 platform provides the framework upon which the web application was built, but out-of-the-box did not provide as user-friendly an environment as the client was looking for. Sections 3.9.1 through 3.9.4 outline each view of the web application and highlight various implementation and design considerations as well as the necessary customizations to make them functional within the application.

\subsubsection{Full Web Page View}

Upon entry into the web application users are presented with a multi-pane web page displaying various tools and information windows. These sections include (see Figure 3.4):

- Title bar

- Tool bar (zoom, pan, etc...)

- Links

- Task pane

- Results pane

- Map Contents pane

- Main Map 


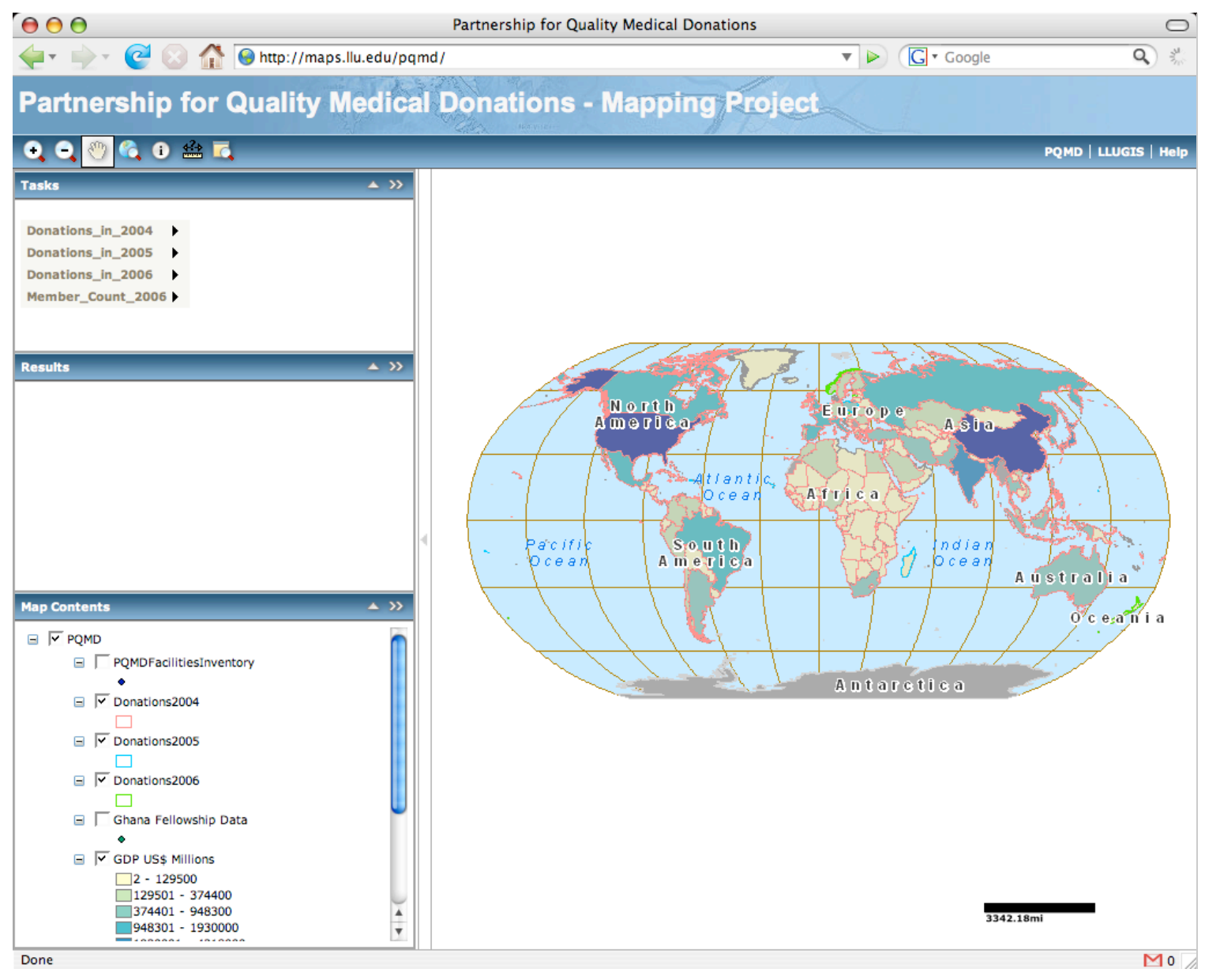

Figure 3.4. Full web page view

The main map view starts at the full global extent and is presented in a Robinson projection. For usability purposes and as a simple navigational aid, all continents and selected oceans are labeled at the initial extent. A six-color choropleth scale depicting Gross Domestic Product by country is used as the base for the map's country layer. Countries that have received one or more PQMD donations are identified on the map via various color outlines corresponding to the year of donation. Outline colors are referenced with donation year in the map's table of contents pane within the application. The map contents pane is customized to be in the open and expanded tree view such that all layers are viewed upon entry into the application. Other items presented in this view are: the maps scale bar, Task pane with task containers closed, and an empty Results pane.

\subsubsection{Zooming and Panning the Map}

Zooming and panning within the main map window are both provided by the packaged ArcGIS Server 9.2 zoom and pan tools; these tools have not been customized. Continent labels are scale-dependent and automatically hide when zoomed in beyond 1:60,000,000 scale. Likewise, country name labels are also scale-dependent and do not appear until the zoom level is inside of 1:50,000,000 scale (see Figure 3.5). The map can be reset to full 
extent using the standard ArcGIS Server full extent tool. The measure tool and magnify tool built into ArcGIS server are also available for use, and have not been customized for the PQMD OMS.

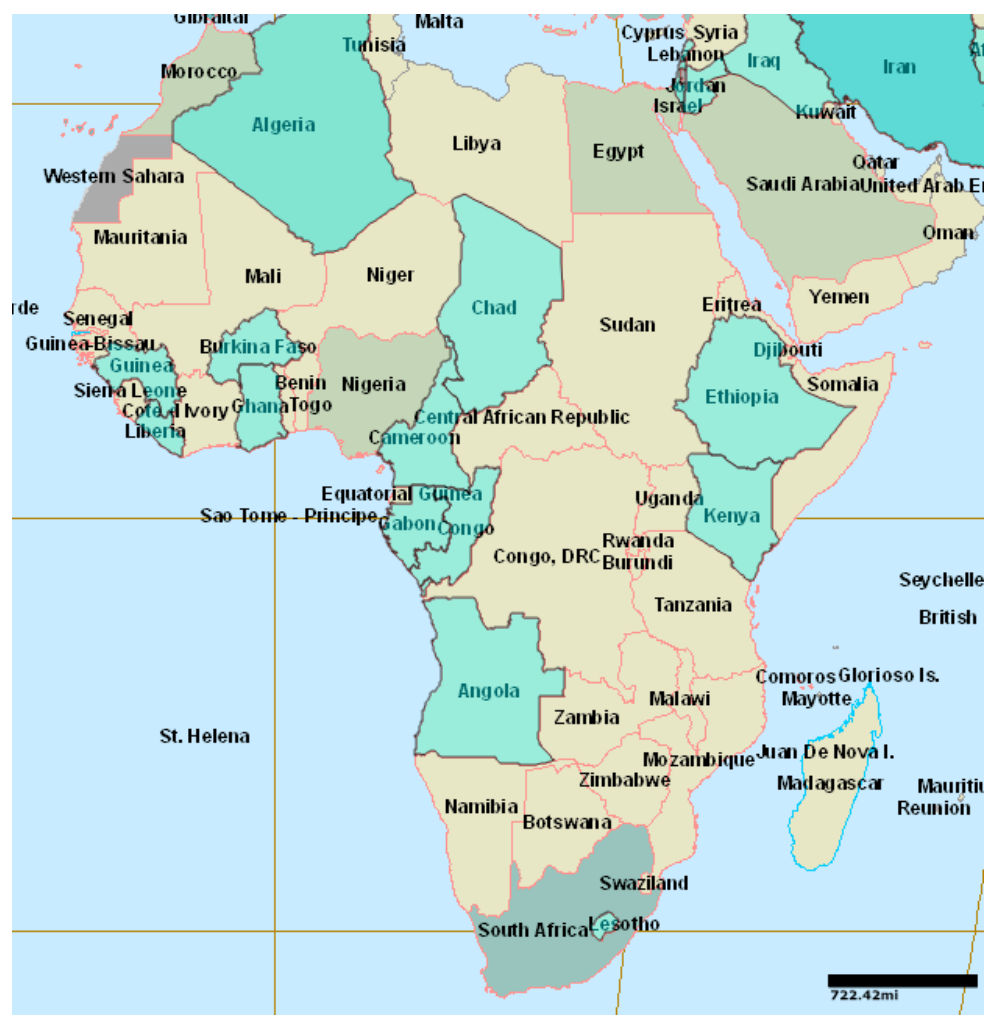

Figure 3.5. Zoomed map view with country labels shown

\subsubsection{Tasks Pane}

The Tasks pane presents users with four task containers: one for each of the donation years 2004, 2005, and 2006 - labeled accordingly, and one for member count 2006. Each of the donation year containers houses two pre-configured queries for the corresponding year's donation data. One query searches the dataset "by country", the other "by donor". Users simply click on the container of the year they would like to search, then choose which way they would like to query the data; they are then presented the selected query window. The query window provides an open ended statement such as "Select a PQMD Member " with a dropdown list of the members that provided donations for that year. The user then selects the member or country they want to query and clicks the search button, at which point the query will run. Results of a successful query display in the Results pane located just below the Task pane. The ArcGIS Server query tool does not accommodate any special characters in the fields it queries, so names such as "Johnson \& Johnson" or "Cote d'Ivoire" were modified to function properly within the PQMD OMS (see Section 4.4 for donor and country name modification details). 


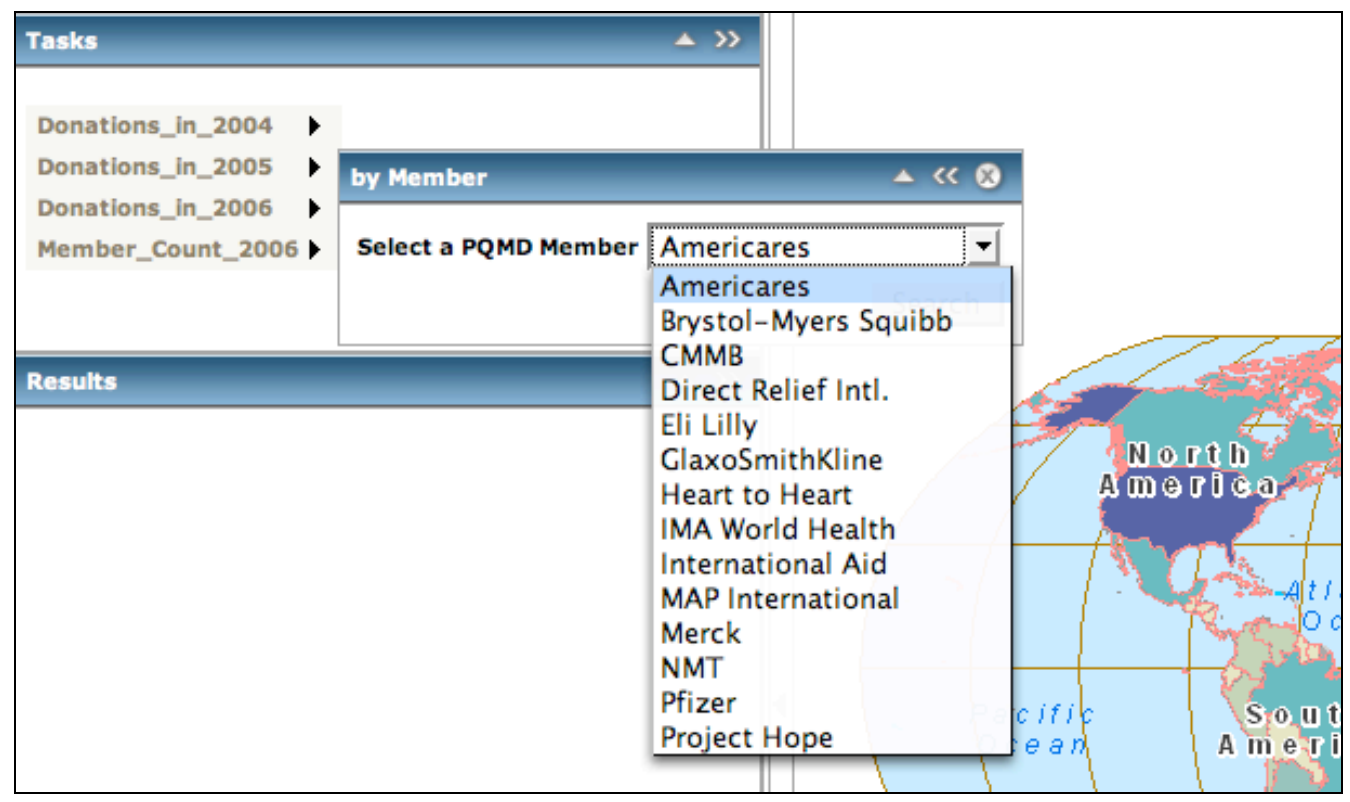

Figure 3.6. Tasks pane and containers

\subsubsection{Results pane}

The Results pane displays the results of queries in the form of a list of either counties who have received donations, donors who have given to a country, or a list of countries with a set number of PQMD members working within. A customization to the standard ArcGIS Server results container was used to increase usability of the application. This customization not only displays a result list in the Results pane, but also cascades the list out two levels and highlights the resulting county or counties on the main map view (Ethiopia, Kenya, etc... in Figure 3.5). The Results pane offers the users the option of cascading the result a third step to see the detailed data attribute view of any individual query result (see Figure 3.7). Right clicking on a result in the results list allows a user to clear all results, remove a result, or rerun the associated task. 


\begin{tabular}{|c|c|c|c|}
\hline Results & & $\Delta>$ & $\gg$ \\
\hline \multirow{2}{*}{\multicolumn{3}{|c|}{$\begin{array}{l}\square \text { by Member (37) } \\
\quad \square \sqrt{\checkmark} \text { Donations2005 (37) }\end{array}$}} & O \\
\hline & & & \\
\hline \multicolumn{3}{|c|}{ Records $1-25$ of $37 \geq$} & \\
\hline \multicolumn{3}{|c|}{$\pm \Gamma$ Afghanistan - Direct Relief Intl., 2005} & \\
\hline \multicolumn{4}{|c|}{$\Xi\lceil$ Bolivia - Direct Relief Intl., 2005} \\
\hline & Country & Bolivia & 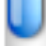 \\
\hline & Organization & \multicolumn{2}{|l|}{ Direct Relief Intl. } \\
\hline & Medical Consumables & 8306 & \\
\hline & Medical Equipment & 9754 & \\
\hline & Other Donations & 0 & \\
\hline & Pharmicuticals & 685152 & \\
\hline & Total Donations & 703211 & \\
\hline & Year & 2005 & \\
\hline & Purpose & & \\
\hline & Label & Bolivia - Direct Reliet & \\
\hline & SHAPE Length & 5026900.61967782 & \\
\hline & SHAPE Area & 917885403092.956 & $\Lambda$ \\
\hline \multicolumn{3}{|c|}{$\pm \sqrt{\square}$ Cambodia - Direct Relief Intl., 2005} & $\nabla$ \\
\hline$C$ & 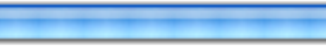 & 44 & \\
\hline
\end{tabular}

Figure 3.7. Results pane (3 levels of results displayed) 



\section{Methodology}

This chapter discusses the specific methodologies used to create the PQMD OMS, focusing largely on "how things were done" and "how the system was built". The chapter provides a description of the project workflow, major tasks, and project schedule. The chapter concludes with three sections detailing the methodologies and techniques employed to create the geodatabase, map document, and web application, which together form the complete PQMD OMS.

\subsection{Project Workflow}

This project was comprised of three main phases (see Figure 4.1). Phase I was System Analysis and Requirements, Phase II was Data \& Map Preparation, followed by Phase III, Web Mapping Application Creation, Customization, and Testing. Each of these phases had a set of specific major tasks associated with it. A list of these major tasks is presented in Section 4.2

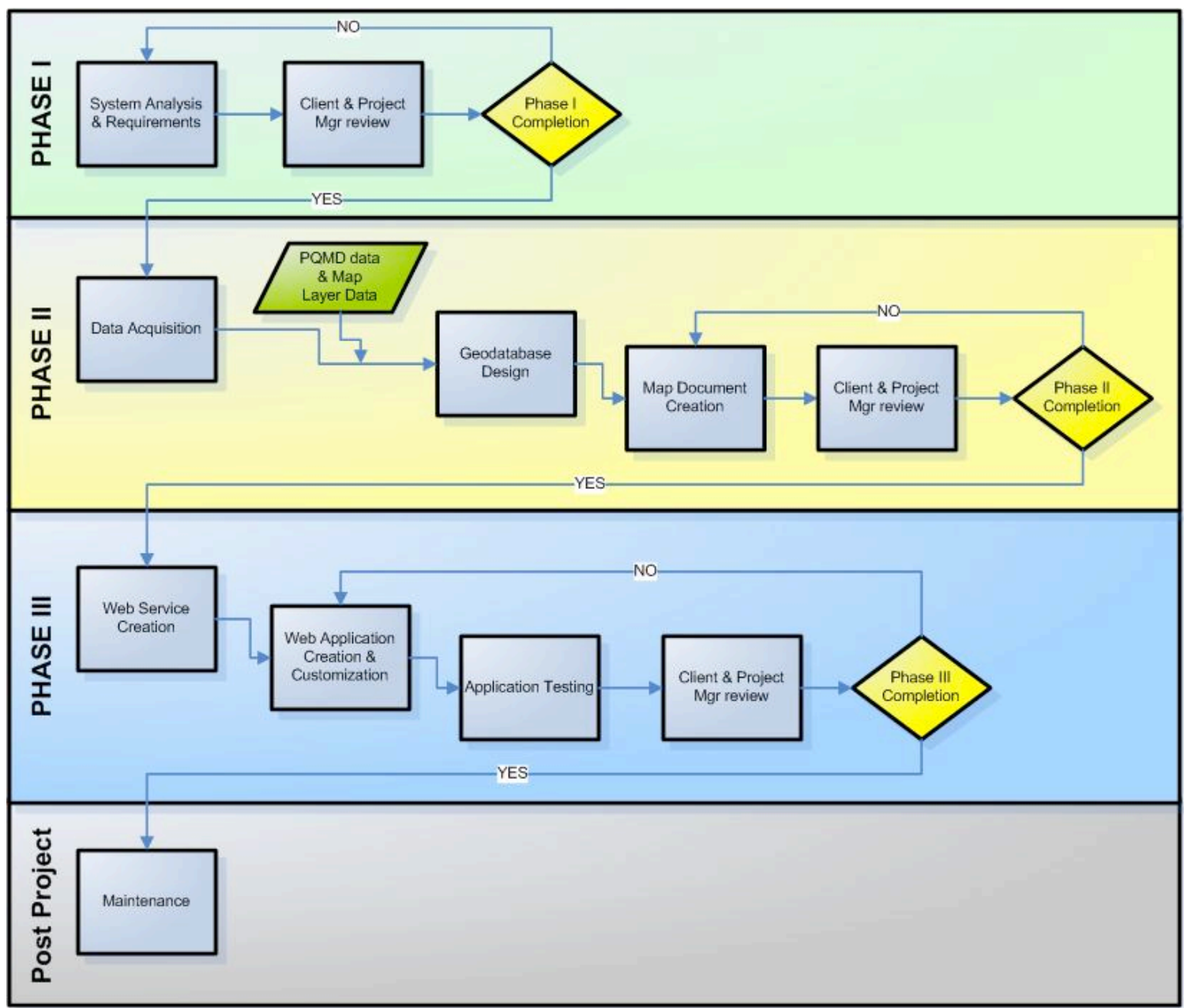

Figure 4.1. Project workflow diagram 


\subsection{Major Tasks}

Each of the project's three phases identified in Section 4.1 included one or more specific tasks. Each task was assigned a unique number, which was used to identify the task in the project budgeting and scheduling tables and charts. These tasks and their unique numbers are outlined in Table 4.1.

Table 4.1. Major Tasks

\begin{tabular}{|c|c|l|}
\hline PHASE & Task & \multicolumn{1}{c|}{ Task Description } \\
\hline \multirow{3}{*}{ II } & 1 & System Analysis \& Requirements \\
\cline { 2 - 3 } & 2 & Data Acquisition \\
\cline { 2 - 3 } & 3 & Geodatabase Design \\
\hline \multirow{3}{*}{ III } & 4 & Map Document Creation \\
\cline { 2 - 3 } & 6 & Web Service Creation \\
\hline I, II, III & 7 & Web Application Creation and Customization \\
\hline $\begin{array}{c}\text { Post } \\
\text { Project }\end{array}$ & - & Project Documentation \\
\hline
\end{tabular}

\subsubsection{PHASE I - System Analysis and Requirements}

Phase I of the project focused on analyzing the problem, discovering requirements for the system, and identifying expected outcomes. Discovery and definition of all client expectations regarding system functionality was critically important during this phase. Equally important in this phase was establishing project constraints in order to prevent scope creep. Items agreed on during this phase were: map document contents, design elements, web map contents, web map queries, and additional expected web map functionality. Prior to the development of the project, the client and project manager reached consensus that all required system elements had been defined during this phase.

\subsubsection{PHASE II - Data \& Map Preparation}

In the second phase of the project, a geodatabase was created to store the necessary data elements of the project. Primary data elements included the PQMD donation data for calendar years 2004, 2005, and 2006; a world gross domestic product (GDP) by country feature class, and world base map data from ESRI Data and Maps 9.2 (ESRI, 2006). The $\mathrm{PQMD}$ provided data in database format (.dbf), which required conversion into a geodatabase feature class. Once the geodatabase was populated, creation of the map document began. A single map document was created and included all data elements (feature classes and tables) stored in the project's geodatabase. All map content items and design elements were considered and completed during this phase and prior to moving into Phase III of this project. This design constraint necessitated a sign off from 
the client and project manager confirming that all agreed upon map elements were present and as desired in the final map prior to the project moving forward.

\subsubsection{PHASE III - Web Application Creation, Customization, and Testing}

Once the client and the project manager agreed to the completion of the base map and its various design elements, the project transitioned into Phase III - Web Mapping Application Creation, Customization, and Testing. During this phase the geodatabase (.gdb) and map document (.mxd) were copied from the desktop system where they were created onto the server system, and the necessary file permissions were set so they could be hosted out to the Internet. A web mapping service was created using the copies of the data $(. g d b, . m x d)$ on the server. A web mapping application was created to consume the web map service, providing the user an environment for interaction with the web service. Both of these processes, web service creation and web application, were performed via ESRI's Web Server Manager interface or via the ArcCatalog desktop interface.

Customization of the application began after the successful creation of the web mapping service and web application via the standard ESRI tools. Microsoft Visual Studio .NET 2005 was used to customize the web application. Customizations included the creation of all queries (by country, by member, num of members in country), custom task results (selection of features), and general look and feel of the web application. This phase concluded with the testing of the application conducted by both the project manager and the client.

\subsection{Schedule \& Time Budget}

This project followed a relatively standard system development cycle starting with a Systems Analysis and Requirements phase (see Figure 4.2).

\begin{tabular}{|c|c|c|c|c|c|c|c|c|c|c|c|c|c|c|c|c|c|c|c|}
\hline \multirow{2}{*}{10} & \multirow{2}{*}{ Task Name } & \multirow{2}{*}{ Start } & \multirow{2}{*}{ Finish } & \multirow{2}{*}{ Duration } & \multirow{2}{*}{\begin{tabular}{|l|}
$Q 207$ \\
Jum \\
\end{tabular}} & \multicolumn{3}{|c|}{ Q307 } & \multicolumn{3}{|c|}{0407} & \multicolumn{3}{|c|}{ at of } & \multicolumn{3}{|c|}{0208} & \multicolumn{2}{|c|}{ Q300 } \\
\hline & & & & & & Jiw & Aog & Sep & Oct & Nov & Dect & Jan & Feb & mar & Apr & May & Jum & Jit' & Aug \\
\hline 1 & \begin{tabular}{|l} 
System Analysis \& \\
Requirements
\end{tabular} & $7 / 2 / 2007$ & $7 / 13 / 2007$ & $10 \mathrm{~d}$ & & P & & & & & & & & & & & & & \\
\hline 2 & $\begin{array}{l}\text { Client \& Project Mgr } \\
\text { review }\end{array}$ & 7/16/2007 & $7 / 16 / 2007$ & Od & & 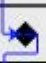 & & & & & & & & & & & & & \\
\hline 3 & Data Acquisition & 7/17/2007 & 7/17/2007 & $1 \mathrm{~d}$ & & b & & & & & & & & & & & & & \\
\hline 4 & Geodatabase Design & $7 / 18 / 2007$ & $8 / 15 / 2007$ & $21 d$ & & & & & & & & & & & & & & & \\
\hline 5 & Map Document Creation & $7 / 18 / 2007$ & $8 / 15 / 2007$ & $21 d$ & & & & & & & & & & & & & & & \\
\hline 6 & $\begin{array}{l}\text { Client \& Project Mgr } \\
\text { review }\end{array}$ & $8 / 16 / 2007$ & $8 / 16 / 2007$ & od & & & 4 & & & & & & & & & & & & \\
\hline 7 & $\begin{array}{l}\text { Web Service \& } \\
\text { Application Development }\end{array}$ & $8 / 20 / 2007$ & $3 / 31 / 2008$ & $161 d$ & & & & & & & & & & & & & & & \\
\hline 8 & $\begin{array}{l}\text { Web App Testing \& } \\
\text { Revision }\end{array}$ & $4 / 1 / 2008$ & $5 / 5 / 2008$ & $25 \mathrm{~d}$ & & & & & & & & & & & & b & & & \\
\hline 9 & $\begin{array}{l}\text { Client \& Project Mgr } \\
\text { review }\end{array}$ & $5 / 6 / 2008$ & $5 / 6 / 2008$ & od & & & & & & & & & & & & 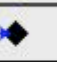 & & & \\
\hline 10 & Project Documentation & $7 / 2 / 2007$ & $6 / 5 / 2008$ & $244 d$ & & & & & & & & & & & & & & & \\
\hline 11 & Paper Due & $6 / 5 / 2008$ & $6 / 5 / 2008$ & od & & & & & & & & & & & & & 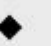 & & \\
\hline 12 & Project Defense & $6 / 19 / 2008$ & $6 / 19 / 2008$ & od & & & & & & & & & & & & & $\bullet$ & & \\
\hline 13 & $\begin{array}{l}\text { Present Project - ESRI } \\
\text { UC }\end{array}$ & $8 / 4 / 2008$ & $8 / 4 / 2008$ & Od & & & & & & & & & & & & & & & 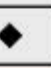 \\
\hline
\end{tabular}

Figure 4.2. Project Schedule 
Once the project manager and the client agreed on the project scope and complete list of project goals, the project moved into Phase II, which was comprised of data gathering, geodatabase design, and map document design. Upon the completion of Phase II, Phase III began, during which the web service was launched and the final web application was built and tested. Each phase concluded with a meeting between the project manager and the client to make sure that all requirements were met for that phase and that there was mutual agreement that the project should move forward. Project documentation ran concurrently with development and spanned the entire duration of the project. The schedule also identifies several post-development milestones related to MS GIS MIP requirements such as the defense and project presentation.

Table 4.2 presents an approximate accounting of the hours spent on each task of the project. Task numbers in this table correspond to the task numbers outlined in Section 4.2, Major Tasks.

Table 4.2. Project Time Budget

\begin{tabular}{|c|l|c|}
\hline Task & \multicolumn{1}{|c|}{ Description } & Hours \\
\hline 1 & System Analysis \& Requirements & 40 \\
\hline 2 & Data Acquisition \& Formatting & 5 \\
\hline 3 & Geodatabase Design & 10 \\
\hline 4 & Map Document Creation & 80 \\
\hline 5 & Web Service Creation & 10 \\
\hline 6 & Web Application Development & 150 \\
\hline 7 & Application Testing \& Revision & 120 \\
\hline 8 & Project Documentation & 400 \\
\hline & & $\mathbf{8 1 5}$ \\
\hline
\end{tabular}

\subsection{Database Development}

A Microsoft Access personal geodatabase was originally selected to support the PQMD OMS. This decision was based on the relative simplicity of the PQMD OMS application and availability of the Access application on the destination hardware. Unfortunately once the application was built and running, performance issues related to the single user design of the Access database were noted. The database was changed to the ESRI file geodatabase in an effort to improve the query performance of the web application.

Performance increased moderately after the database was changed from Access to the file geodatabase; therefore the final version of the PQMD OMS uses an ESRI ArcGIS 9.2 file geodatabase. Appendix A provides a complete diagram of the PQMD OMS file geodatabase. If the PQMD OMS use increases significantly, an enterprise class database such as MS SQL will need to be considered to replace the file geodatabase. 


\subsubsection{Donations200X Feature Classes}

The raw PQMD donation data did not contain the necessary spatial data attributes necessary for querying within the ArcGIS Server environment. A join was necessary to add the spatial data to the donation datasets. This join was performed in ArcGIS Desktop between the raw PQMD annual donation data files and the world countries data file (Cntry00). The ArcGIS Desktop query table creation tool was used to join these two data sets and create a single Donations $200 X$ feature class for each donation year as shown in Figure 4.3.
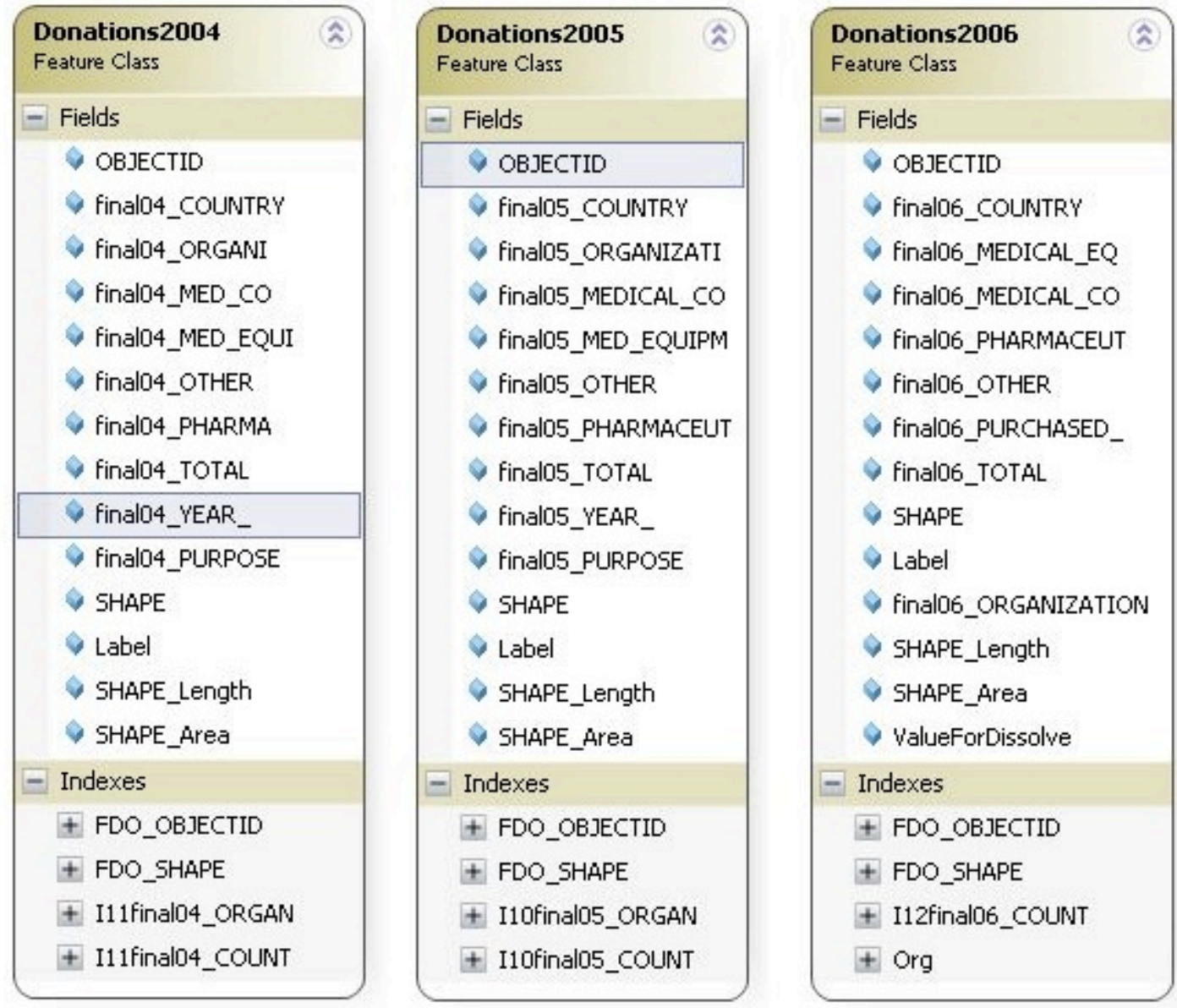

Figure 4.3. Donations200X Feature Classes

The join is a many-to-many relationship as there are many donations to many countries. Using "country name" in both donations (Final0X.dbf) and country data tables (Cntry00), the query table tool was used to add spatial data by county to each donation so that they could be properly represented on the map (see Figure 4.4). 


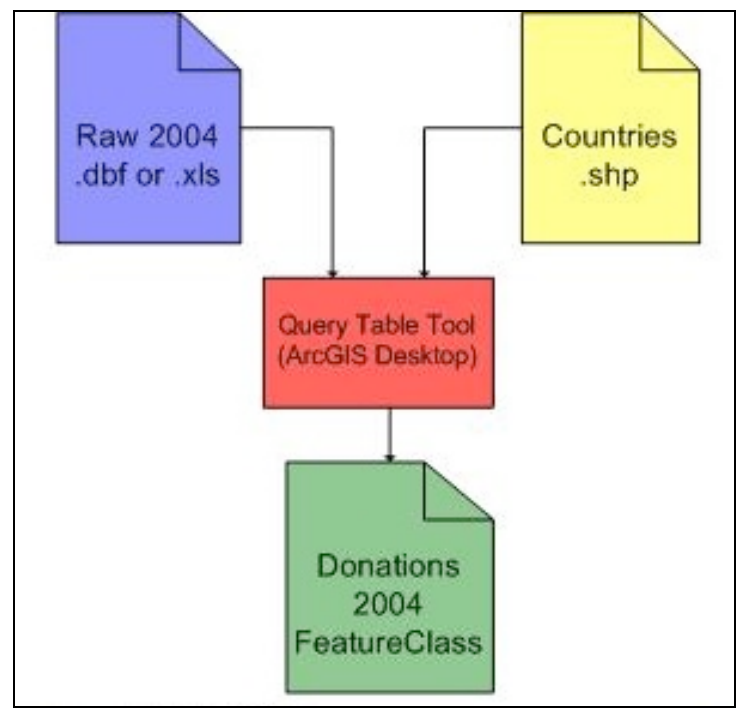

Figure 4.4. Query Table Tool

The query table join was made using the country name field in both the annual donations table and the country table. Because this join was made using a text field, it was important that spelling and any special characters such as hyphens or apostrophes matched within the tables, otherwise the query tool would not work. During the creation of the Donations $200 X$ feature classes, special attention was paid to any country with more than one word or special characters in its name. Table 4.3 provides a list of country names that did not match or caused omissions in the output feature classes. All of these omissions were corrected with the exception of one country. Within the three years of donation data provided, there were two donations made to the country of Kosovo. Until the year 2008 Kosovo was not recognized as a country and is still struggling for its independence from Serbia. For this reason, Kosovo is not listed in the ESRI countries feature class, it does not have geometry, and cannot be joined during the query table creation process. This issue was discussed with the client and it was decided to omit these two donations from the PQMD OMS.

Table 4.3. Country Name Corrections

\begin{tabular}{|l|l|}
\hline \multicolumn{1}{|c|}{ Name Problem } & \multicolumn{1}{c|}{ Correction } \\
\hline Bahaman Islands & The Bahamas \\
\hline Central African Repub. & Central African Republic \\
\hline Columbia & Colombia \\
\hline Cote d'Ivoire or Ivory Coast & Cote d Ivoire \\
\hline East Timor & Timor Leste \\
\hline Gambia & The Gambia \\
\hline Marshall Islands & Marshall Is. \\
\hline St. Vincent \& the Grenadines & St. Vincent \\
\hline U.S.A & United States \\
\hline
\end{tabular}


In addition to the correction of some of the country names, several of the PQMD donor names needed to be modified. Donor names were listed with multiple spellings and were not consistent across donation years and thus required correction. As was previously discussed in Section 3.9.3, the ArcGIS Server query tool cannot handle special symbols such as the "\&" in the name Johnson \& Johnson. All PQMD donor name corrections as identified in Table 4.4 were discussed and approved by the client.

Table 4.4. Donor Name Corrections

\begin{tabular}{|l|l|}
\hline \multicolumn{1}{|c|}{ Name Problem } & \multicolumn{1}{c|}{ Correction } \\
\hline Direct Relief International or DRI & Direct Relief Intl. \\
\hline Heart 2 Heart & Heart to Heart \\
\hline Johnson \& Johnson & Johnson $\mathrm{n}$ Johnson \\
\hline
\end{tabular}

Other than the name corrections outlined in tables 4.3 and 4.4, the PQMD annual donation data in the newly created Donations $200 X$ feature classes remains as it was in the raw .dbf files. In addition to the country and donor name attributes, the feature classes contain attributes for dollar amounts for each of the donation types. The donation types are medical consumables, medical equipment, pharmaceuticals, other supplies, and total donation dollars. A special display attribute was added to each of the Donation200X feature classes called "Label." The value for this attribute is simply a concatenation of "Country Name + Donor Name + Donation year" and is used for query result display within the web application. In an effort to maximize query performance, field indexes were created on country name and organization name in each donations feature class. 


\subsubsection{Countries Feature Class}

The countries feature class is the ESRI Data \& Maps 9.2 (ESRI, 2006) Cntry00 countries feature class. Several fields were added to the countries feature class to support display and query functionality within the PQMD OMS. A field for gross domestic product (GDP) was added and contains values for GDP for each country. The client requested that GDP be used as the base symbology for each country.

\begin{tabular}{|c|c|c|}
\hline \multicolumn{2}{|c|}{$\begin{array}{l}\text { Continents } \\
\text { Feature Class }\end{array}$} & $\hat{\imath}$ \\
\hline \multicolumn{3}{|c|}{ - Fields } \\
\hline & OBJECTID & \\
\hline & Shape & \\
\hline & CONTINENT & \\
\hline & SQMI & \\
\hline \multicolumn{3}{|c|}{ SQKM } \\
\hline \multicolumn{3}{|c|}{$\checkmark$ label } \\
\hline \multicolumn{3}{|c|}{$\checkmark$ Shape_Length } \\
\hline \multicolumn{3}{|c|}{ Shape_Area } \\
\hline \multicolumn{3}{|c|}{ - Indexes } \\
\hline \multicolumn{3}{|c|}{ + FDO_OBJECTID } \\
\hline & + FDO_Shape & \\
\hline
\end{tabular}

\begin{tabular}{|c|c|}
\hline & $\begin{array}{l}\text { ntry00 } \\
\text { eature class }\end{array}$ \\
\hline \multicolumn{2}{|c|}{ - Fields } \\
\hline \multicolumn{2}{|r|}{ OBJECTID } \\
\hline \multicolumn{2}{|r|}{ Shape } \\
\hline \multicolumn{2}{|r|}{$\checkmark$ CNTRY_NAME } \\
\hline \multicolumn{2}{|r|}{$\diamond$ FIRST_FIRS } \\
\hline \multicolumn{2}{|r|}{$\mathrm{GDP} 2$} \\
\hline \multicolumn{2}{|r|}{ Shape_Length } \\
\hline \multicolumn{2}{|r|}{ Shape_Area } \\
\hline \multicolumn{2}{|r|}{ MemberCount_2006 } \\
\hline \multicolumn{2}{|r|}{ DonationTotal_2006 } \\
\hline \multicolumn{2}{|r|}{ DonationTotalLabel_200 } \\
\hline \multicolumn{2}{|c|}{ - Indexes } \\
\hline \multicolumn{2}{|r|}{ + FDO_OBJECTID } \\
\hline \multicolumn{2}{|r|}{ + FDO_Shape } \\
\hline \multicolumn{2}{|r|}{ + Name } \\
\hline \multicolumn{2}{|r|}{+ count } \\
\hline
\end{tabular}

\begin{tabular}{|c|c|}
\hline $\begin{array}{l}\text { WORLD30 } \\
\text { Feature Class }\end{array}$ & $\hat{\imath}$ \\
\hline \multicolumn{2}{|l|}{ - Fields } \\
\hline OBJECTID & \\
\hline$\checkmark$ shape & \\
\hline WRLD30_ID & \\
\hline Label & \\
\hline Shape_Length & \\
\hline Shape_Area & \\
\hline - Indexes & \\
\hline † FDO_OBJECTID & \\
\hline + FDO_Shape & \\
\hline
\end{tabular}

Figure 4.5. Countries and Base Map Feature Classes

Three additional fields were added to support the "2006 Member Count" query. Using the dissolve tool in ArcToolbox, a count of members in each country was performed against the Dontations 2006 feature class, and the resulting data was added to the country feature class in the MemberCount_2006 field. In addition to the member count, a summation of the total donation dollars was calculated and populated into the DonationTotal_2006 field. The DonationTotalLabel_2006 field is simply a reformatting of the total donations number for display purposes within the web app. Field indexes were created on country name and the member count fields, in an effort to maximize query performance.

\subsubsection{Base Map Feature Classes - WORLD30 \& Continents}

The WORLD30 feature class is used to provide the world oceans background and longitude and latitude lines in 30 degree increments. The WORLD30 feature class also 
comes from the ESRI Data \& Maps 9.2 (ESRI, 2006). The only customization to the WORLD30 feature class was the addition of a label field to facilitate the labeling of the Pacific, Atlantic, and Indian Oceans. The three labels were placed in the three longitude/latitude grid cells that best represent the oceans for the web mapping environment.

The Continents feature class is provided by the ESRI Data \& Maps 9.2 (ESRI, 2006) and is only used to provide continental labels at full map extent. The Continents and WORLD30 feature classes can be viewed in the complete geodatabase diagram in Appendix A.

\subsubsection{Client requested non-project point feature classes}

During the development of the PQMD OMS, the client requested to use the PQMD OMS as a delivery mechanism for two point feature classes. The PQMD has sponsored several projects to collect the geographic coordinates of their worldwide facilities. These two point feature classes result from those projects. The two feature classes represent the PQMD facilities in the countries of Ghana, Africa (Ghana_finalxy) and Honduras, Central America (PQMDfacilitiesInventory). The PQMD would like to integrate their point data and their donation data at some time in the future (see Section 6.1, Future Work). These feature classes were added to the PQMD OMS project as a proof-ofconcept and the client was most appreciative. The inclusion of these datasets showed little to no performance impact on the overall performance of the PQMD OMS. 


\subsection{Map Document Development}

The PQMD OMS map document was created using ArcGIS Desktop 9.2. The map document contains all six of the feature classes described in the previous section of this document, as well as the two point features classes the client requested that are outside the scope of this project. The map is projected in a Robinson projection, as this projection is known for producing a pleasing compromise between equal-area, conformal, and equidistant projections and it is considered to look right for world maps (Mathworks, 2008; Snyder \& Voxland, 1989).

\subsubsection{Donation data}

Each Donation $200 X$ polygon feature class is symbolized using hollow features with unique colored outlines for each donation year. Donation year outline colors are as follows: 2004 - red, 2005 - blue, and 2006 - green. These feature classes and their corresponding symbology are shown Figure 4.6.

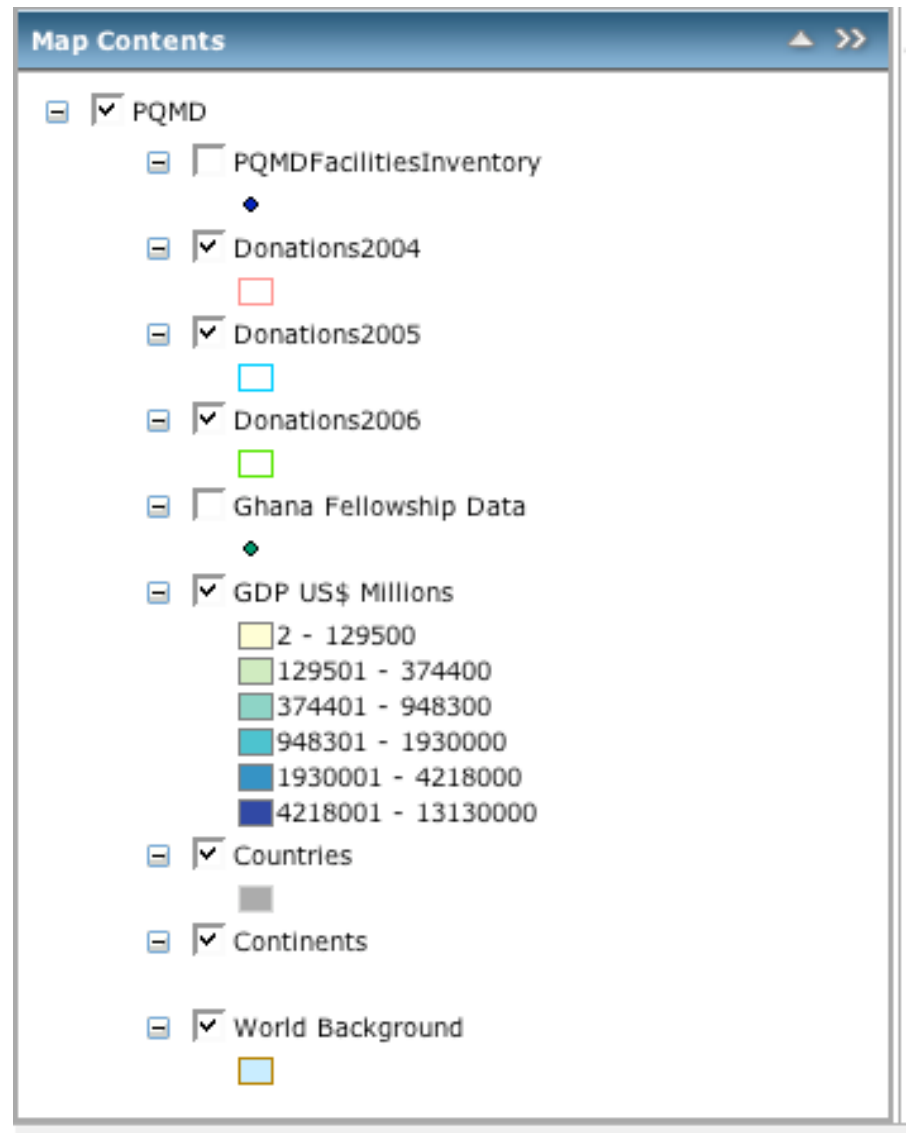

Figure 4.6. Table of Contents

\subsubsection{Countries}

The countries layer (Cntry00) represents all of the world's countries. All countries in the main countries layer are symbolized the same using a medium grey color. Countries are labeled using the name field. Country name labels use a 9 point Arial bold font face, 
appear only once per feature, and overlap of labels has been minimized. Country labels are set to a scale dependency so that they appear only at a scale of 1:50,000,000 or larger.

The country feature class is also used to display gross domestic product (GDP) values. The GDP layer uses a six level choropleth symbology to display the countries GDP with values ranging from $\$ 2$ to $\$ 13,130,000$ (millions). Lower GDP values are represented by light colors starting with a light yellow and ramp up to navy blue for the highest GDP values as seen in Figure 4.7. The GDP layer sits above the country layer in the map's table of contents such that the GDP is the visible symbology for countries in the map document (see Figure 4.6).

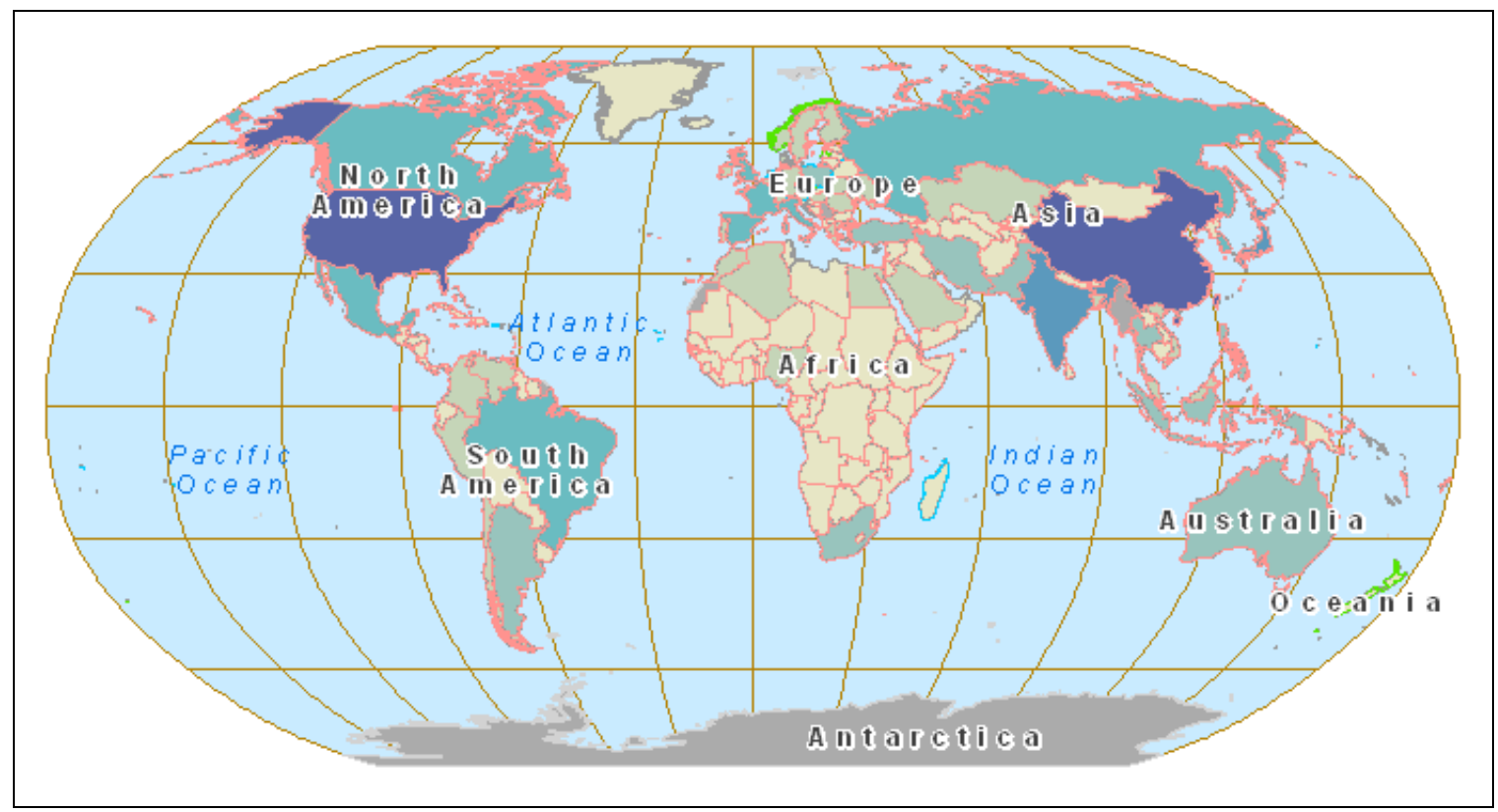

Figure 4.7. Map showing GDP, Continents, and Oceans

\subsubsection{Continents and Oceans}

The Continents feature class is used in the map document only to provide continental labels and does not have feature symbology. All continents and Oceania are labeled in a black non-serif font with 0.5 point white halo.

The WORLD30 base grid and ocean layer is used as a background for the map. Pacific, Atlantic, and Indian oceans have been labeled using the standard medium blue italics symbology for oceans (see Figure 4.7).

\subsection{Web Application Development}

The basic PQMD OMS web application was created using the ArcGIS Server Manager web template. The ArcGIS Server Manager wizard was used to set up the main components of the web application including making the connection to the map's web service, the basic map window, map table of contents, and the basic task framework. Microsoft Visual Studio .NET 2005 was then used to further customize the site. Major 
customizations included the creation of all nine of the application's queries, the installation and configuration of a custom task results container, and customization to the look and feel of the application.

\subsubsection{Query Tasks}

Each of the nine queries available in the application was custom built in the .NET environment using the ArcGIS Web Application Development Framework (ADF) tools. There are three different types of queries used in the PQMD OMS: by member, by country, and number of members in country. The first two types of query, by member and by country, are available for each of the three donation years (total of six queries). These query tasks run against the Donations200X feature classes and return the names of either countries where a particular member is working, or the name of organizations working in a selected country for a given year. These queries are organized in query containers by donation year so that a user simply selects a donation year and then selects to query by member or by country. A drop-down list of PQMD members and countries was built to further simplify the query process. After selecting the query type the user simply needs to choose, from the drop down list, the name of the member or country they would like to query.

The remaining three queries all relate to counting the number of members working in any given country. These queries are designed to query only the most recent donation data set available, currently 2006. The three queries are housed in a separate task container labeled "member count 2006" and run against the cntry00 (countries) feature class. The queries simply return results based on the number present in the donation_total_2006 field for each country. The three queries are: more than or equal to, less than or equal to, and equal to. Once the user selects the query they want to run they simply need to enter the number of members they are looking for and the query will return the results in both the map and the task results pane.

\subsubsection{Custom Results Container (ZoomToResults)}

ArcGIS Server 9.2 provides a basic task results container within the web application environment. However, the basic results container is fairly limited in its functionality and customization options. One of the main features lacking in the basic results container is the inability to highlight the corresponding map elements of a queries result. For these reasons, a custom results container was added to the PQMD OMS to enhance the user experience.

The custom results container selected for this project is called ZoomToResults, which was developed by Tom Brenneman and Rex Hansen of the ESRI server Development team (Brenneman \& Hansen, 2007). Using the Visual Studio .NET environment, the source code was compiled into a single windows .dll and added to the PQMD OMS. Once in the application, ZoomToResults was added to each query task as a custom results container. ZoomToResults was then configured to automatically select and highlight the map features returned in query results. Combined with the basic task results container, ZoomToResults allows the users to see both a list of queried countries and the resulting countries highlighted on the map. 


\subsubsection{Look and Feel}

The PQMD OMS uses an out-of-the-box ArcGIS Server 9.2 web application template. However, the template has been customized in the Visual Studio .NET environment in order to accommodate some specific data elements of the PQMD OMS. Several elements of the basic template were removed such as the overview map and the north arrow/compass rose. Both of these elements provided nice functionality for the web application, unfortunately they took up a considerable amount of screen real estate. These two elements were removed due to the fact that they were so large, and the navigation functionality they provided could be achieved via the pan and zoom tools. The left side pane containing tasks, results, and table of contents was enlarged

horizontally to improve the viewing of task results and to further maximize the available screen real estate. Although this change reduced the size of the map window, it made it significantly easier to view task results in the expanded views. The client also requested that the map's table of contents be present and fully expanded such that it would be easy to identify active versus non active layers and to decipher feature symbology. 



\section{Implementation \& Analysis}

\subsection{Application Testing}

The application testing of the PQMD OMS was done directly with the client in an iterative model during the design and buildup of the application. This is a very nontraditional model but it worked well in this environment since the project manger had near daily contact with the client. The client also requested to be participatory in the development and usability testing of the application. The testing approach was a collaborative effort between client and developer and continued until both were satisfied with the usability of the application, within the confines of the project schedule.

\subsubsection{Test Scope}

Primary components tested and questions addressed within the PQMD OMS were:

- Visual components - Was the map symbology understandable? Were the web application windows appropriately sized and laid out in a logical and usable order?

- Queries - Did they work? Did they provide accurate and complete results? Were the queries organized in a logical and usable manner?

- Results Pane - Were the results clearly identified? Were the results usable in the format displayed? Were the results displayed in a timely maner?

All of the above questions were considered within the limitations of the ArcGIS Server Web Application environment requested by the client. Although it provides a robust and powerful online GIS, the ArcGIS Server has some limitations to its front-end web application windows, and the development of the PQMD OMS was forced to work within those limits. The client was well apprised of those limits and was willing to work within them.

\subsubsection{Test Environment \& Schedule}

Since the PQMD OMS is an online application hosted on the Internet, it could be tested in any environment with a broadband Internet connection, a computer, and a modern web browser. The client had requested that he be able to informally exercise the system with student groups (at Loma Linda University) and select members of the PQMD organization in exchange for usability feedback during the month of April 2008. The project manager also conducted similar application previews within the developer and GIS communities to solicit informal feedback and recommendations on the server functionality, performance, and specific cartographic and visual elements. These groups provided a diverse set of web literacy levels from which valuable usability feedback was gleaned. Testing of the PQMD OMS occurred throughout the development of the system, with final application testing occurring in April 2008. All testing was complete by May 1 st 2008 . 


\subsubsection{Test Acceptance}

The client and project manager met during the second week of May 2008 to review the PQMD OMS features and functions. It was agreed that all functionality and features were present within the PQMD OMS as had originally been identified in the project plan. The client and project manager are both in agreement that development and additional functionality of the PQMD OMS will continue after the project manager completes the University of Redlands MS GIS program.

\subsection{Deployment}

Deployment of the PQMD OMS was somewhat unique as the system was built and tested on the client's final production hardware. Because the application was already running on the client's hardware, it did not require further installation on different hardware. The final production datasets were already in place and did not require further manipulation or data loading. The database was also complete and present within the production hardware.

Once the PQMD OMS was complete as per the requirements in the project plan, the client and project manager agreed that any and all future development should occur on the client's test server system. Since the PQMD OMS is considered a "live" production system, it needs to be available in an uninterrupted state for client use. The client's test server closely mimics the production hardware and allows a mirror of the production system such that updates to the system can be fully tested prior to roll out. The client's test system is outside of the scope of this MS GIS MIP.

\subsubsection{Training}

The client has not requested a formal training program on the use of the new PQMD OMS. The hope is that the system will be simple enough that someone with basic web knowledge will be able to use it effectively with no formal training. An application help module has been created and is available within the standard online help in the ArcGIS Web application. The diverse geographic locations of the PQMD member organizations would necessitate some level of web collaboration tool to facilitate a formal training of the system and is outside the scope of this project. The project manager has provided a thorough overview or "train-the-trainer" session for the client, such that he can demonstrate the system to the PQMD board and member organizations at their 2009 annual meeting.

\subsubsection{Basic Operations Plan}

The PQMD OMS is a web application that requires little ongoing maintenance aside from the addition of future annual donation data. There are, however, a few important procedural items that should be noted when and if the system needs to be taken offline for power outages, system upgrades, or data updates. The PQMD OMS is dependent on two ArcGIS services, which must be started in the correct order and fully running in order for the application to function properly. Likewise, if the server needs to be taken offline, these processes should be stopped in the correct order. The two ArcGIS Server processes are: 
- Web Service - PQMDproto

- Web Application - PQMD

The ArcGIS Server service needs to start during machine startup, prior to any users attempting to access the website. These services may be started and stopped manually using either the ArcGIS Server Manager interface (remote or local), or using an ArcCatalog connection (local only). These services need to be stopped and started correctly should changes be made to any of the supporting data, or if the server needs to be shutdown or restarted.

The files necessary to support the PQMD OMS are located on the client's ArcGIS Server in the data share called "DATA" and are in a directory labeled "PQMD" (see Appendix B). This location houses the geodatabase and the PQMD.mxd file upon which the PQMDproto web service is based.

Someone trained in the management of the ArcGIS Server 9.2 product should perform the above operations. Details on the ongoing maintenance, management, and procedural elements of the ArcGIS Server product are not provided here and are outside the scope of this project.

After the completion of this project for the University of Redlands, the project manager will continue development and maintenance of the PQMD OMS until he or the client terminate the relationship.

ESRI has announced plans to release ArcGIS Server version 9.3 during the summer of 2008. At this time it is unknown whether the PQMD OMS will require significant modification to operate under the 9.3 release of the server product. Dr. Bryan Baker has indicated that most functionality in basic ArcGIS web applications should migrate to the new version but could not provide specifics. The project manager looks forward to working with the client to evaluate version 9.3 and the identification of a migration plan (outside of the $\mathrm{U}$ of $\mathrm{R}$ project).

\subsection{Analysis}

This project provided several interesting technical challenges during the development cycle. The most complex of these came early in the project during database design. Traditional database design encourages the compartmentalization of like objects into separate containers (tables). Applying that strategy to this project, one would likely store spatial country data in one table, organization data in another table, and the donation data in yet another table. After the tables were created a relationship between the three features would be used to query individual donation instances. Unfortunately, the ArcGIS Server query task is not set up (out-of-the-box) to query across multiple tables or layers and expects all data for the query result to come from a single table. This problem is further exacerbated by the fact that within the PQMD data, there are multiple donations, made by multiple organizations, to multiple countries, over multiple years. The ArcGIS Desktop Query Table tool provided a relatively simple solution to this complex and daunting problem. The tool joined the spatial attributes of the country data to each row in the annual donation data, outputting a single queryable layer for use in the web application. Although the final output feature class is a rather large flat file with many diverse attributes, it provided a simple and functional solution to the problem. 
Another solution to the problem would have used ArcObjects programming to enable a multi-table query in the ArcGIS Server environment, but this approach required programming skills beyond the capacity of the project manager.

The second development challenge encountered during the development of the PQMD OMS came near the end of the project during a software upgrade. The development time for this project spanned more than eleven months, during which ESRI released several service packs to both their desktop and server software. ESRI recommends not only keeping up-to-date with service packs but also matching service pack levels across the product lines. The PQMD OMS was developed using ArcGIS Desktop and Server version 9.2 service pack 3 until the final month of the project. ESRI released service pack 5 during the last month of the project. Service pack 5 was installed on both the desktop and server version of the software in the hope that it might solve several minor task result display issues. Unfortunately the service pack did not solve the display issues, but worse, caused the web application to stop functioning altogether. The service pack broke the zoom-to-results tool, which had been built for service pack 3. Because zoomto-results was not built by ESRI and was not part of the core product, it was not tested for compatibility with service pack 5. After three days of trying to determine what was wrong, the problem was discovered and subsequently resolved by recompiling the zoomto-results tool with a mix of libraries from service packs 3 and 5. Lesson learned: always test service packs on a development system prior to installation on a production system, particularly if third party software is installed.

The real benefits of the system became apparent once the technical challenges were solved and the system became functional. The PQMD OMS provides new functionality and new information to the PQMD management team and the PQMD member organizations. The most obvious and immediate benefit realized by the client is the immediacy and ease of access to the donation data. Even during the development of the system, the client was using the system and sharing success stories. The first of these stories was a call from a PQMD member wanting to make a donation to country in the Caribbean. The PQMD member asked if any other members were working in the country where they wanted to send a donation. The client quickly launched the web application, performed a by country query and had a result within seconds. The client relates that the PQMD member was amazed at the speed of his response.

In the wake of the recent cyclone in Myanmar and earthquake in China (both in May 2008) the client has related that the PQMD OMS provides previously unrealized benefits. Both Myanmar and China have had PQMD members working within their borders and both countries have enforced significant restrictions on allowing outside aid into the countries post disaster. The client relates that the PQMD OMS allows them to quickly evaluate which PQMD members already had a presence in country and what supplies may already be on the ground. By identifying the PQMD members already on the ground the PQMD can funnel donations through these member organizations to maximize their collective donations and expedite the aid.

Some concern has been raised about the completeness of the annual PQMD donation datasets such as missing member organizations, or missing donations. The hope is that the PQMD OMS will help to identify these data gaps and that the PQMD member organizations will want to have their data included and thus provide updates to the 
PQMD management for inclusion in the PQMD OMS. The project manager is willing to update the annual donation datasets to reflect the new data that may come in.

Server performance issues are not anticipated due to the modest numbers of expected users of the PQMD OMS. However, if use exceeds the server's capacity, this will be perceived as a positive problem, additional resources will be acquired, and the system will be scaled up to accommodate the increased load. 



\section{Summary and Conclusions}

Countries around the globe rely on the medical product donations of the PQMD and its member organizations. Built using the latest ArcGIS Server 9.2 web technologies, the PQMD online mapping system allows members to visualize their donations along with the donations of the other PQMD members. The application provides a user-friendly environment within which the PQMD donation data may be both visualized and analyzed in order to identify unmet medical product needs. The system also aids in the discovery of areas of duplicate donations, in an effort to improve resource management. Lastly, the system provides a new method of communicating member activities between the PQMD member organizations.

\subsection{Future work}

Although the PQMD OMS meets all of the initial project goals, and objectives, there are a number of future enhancements that would increase the systems usability and overall value to the client. Below is a list of the features or changes that could enhance the system:

- Provide a custom results window that displays the list of countries or member organizations in a structured report form rather than a tree view.

- Include the ability to print out a structured report of query results.

- Collapse the three member count queries into a single query which allows the user to choose the greater than, less than, or equal to operators within the query window and also run the query against any or all of the PQMD donation datasets.

- Integration of the PQMD worldwide facilities point data (currently being collected PQMDFacilitiesInventory and Ghana Fellowship Data feature classes) within the donation data such that one could determine the actual location of the donated products on the ground in the receiving country.

- Include a global aerial imagery layer or service. This would provide a more natural backdrop to the map and will become critical if the point data project matures within the PQMD OMS.

- Migrate the database to an enterprise class database such as Oracle or SQL allowing the possible integration with PQMD transactional databases for real-time donation data updates.

- Redesign the architecture of the database and application so that multiple years of donation data can be queried via a single set of queries. This would increase the long-term scalability of the application significantly.

- ESRI has announced ArcGIS server 9.3 is to be released during the summer of 2008. The PQMD has already expressed the desire to move the PQMD OMS to the new version of the server software.

In addition to the above feature enhancements, the PQMD OMS would benefit from a visual facelift performed by someone with real world web and graphic design experience. The current system is based on the ArcGIS Server web application template, which is 
functional, but quite bland. A good web-graphic designer and .NET programmer could work alongside a GIS professional to migrate the components of the existing PQMD OMS into a more visually appealing web application. 


\section{References}

Anderson, G., \& Moreno-Sanchez, R. (2003). Building Web-Based Spatial Information Solutions around Open Specifications and Open Source Software. Transactions in GIS, 7(4), 447-466.

Benini, A. A., Conley, C. E., Shdeed, R., Spurway, K., \& Yarmoshuk, M. (2003). Integration of Different Data Bodies for Humanitarian Decision Support: An Example from Mine Action. Disasters, 27(4), 288-304.

Boulos, M., \& Honda, K. (2006). Web GIS in practice IV: publishing your health maps and connecting to remote WMS sources using the Open Source UMN MapServer and DM Solutions MapLab. International Journal of Health Geographics, 5(1), 6.

Brenneman, T., \& Hansen, R. (2007). ArcGIS Server Development Blog. Zooming to task results automatically. Retrieved Oct 7, 2007, from http://blogs.esri.com/Dev/blogs/arcgisserver/archive/2007/08/28/Automaticallyzooming-to-task-results.aspx

Craddock, S. (2007). Antiretrovirals and the body politics of inequality. Paper presented at the Association of American Geographers, San Francisco, California April 17$21,2007$.

Daniel, D. J. (2003). Using GIS in alumni giving and institutional advancement. New Directions for Institutional Research, 2003(120), 77-89.

ESRI. (2006). ESRI Data and Maps 9.2. Redlands, CA: ESRI Press.

González-Casillas, L. M., \& Pérez, J. I. C. (2005). Rapid Cartography For Humanitarian Aid. Paper presented at the International Cartographic Association Annual Meeting, A Coruna, Spain.

Haeni, R. E. (2005). Supporting Humanitarian Activities: Operational Assistance and Security Information System. Paper presented at the ESRI International User Conference, San Diego, CA.

Hoppen, S. (2001). A Humanitarian Relief GIS for East Africa. Paper presented at the ESRI International Users Conference, San Diego, CA.

Kamadjeu, R., \& Tolentino, H. (2006). Web-based public health geographic information systems for resources-constrained environment using scalable vector graphics technology: a proof of concept applied to the expanded program on immunization data. International Journal of Health Geographics, 5(1), 24.

Krug, S. (2000). Don't Make Me Think! A Common Sense Approach to Web Usability. Berkeley, CA: New Riders Publishing.

Maclachlan, J. C., Jerrett, M., Abernathy, T., Sears, M., \& Bunch, M. J. (2007). Mapping health on the Internet: A new tool for environmental justice and public health research. Health \& Place, 13(1), 72-86.

Mathworks. (2008). Mapping Toolbox - Robinson Projection. Retrieved May 27, 2008, from

http://www.mathworks.com/access/helpdesk/help/toolbox/map/index.html?/acces s/helpdesk/help/toolbox/map/robinsonprojection.html

Nelson, J., \& Prescott, D. (2003). Business and the Millennium Development Goals: A Framework for Action: The International Business Leaders Forum.

Snyder, J. P., \& Voxland, P. M. (1989). An Album of Map Projections (No. 1453): U.S. Geological Survey. United States Government Printing Office. 
Tanser, F. C., \& Le Sueur, D. (2002). The application of geographical information systems to important public health problems in Africa. International Journal of Health Geographics, 1(1), 1476-1072X (Electronic).

Theseira, M. (2002). Using Internet GIS technology for sharing health and health related data for the West Midlands Region. Health \& Place, 8(1), 37-46.

Wiafe, S., Haglund, A., \& Tong, E. (2007). Understanding Medical Products Donation with GIS: The Partnership for Quality Medical Donations (PQMD) approach. Paper presented at the Canadian Public Health Geomatics Conference, Ottawa, Canada. 


\section{Appendix A - Complete Geodatabase Diagram}

\begin{tabular}{|c|c|c|}
\hline \multicolumn{2}{|c|}{$\begin{array}{l}\text { Donations2004 } \\
\text { Feature Class }\end{array}$} & $\hat{\imath}$ \\
\hline \multicolumn{3}{|c|}{ - Fields } \\
\hline & $\vartheta$ OBJECTID & \\
\hline & $\vee$ final04_COUNTRY & \\
\hline & $\diamond$ final04_ORGANI & \\
\hline & final04_MED_CO & \\
\hline & $\diamond$ final04_MED_EQUI & \\
\hline & final04_OTHER & \\
\hline & $\diamond$ final04_PHARMA & \\
\hline & Final04_TOTAL & \\
\hline & Final04_YEAR_ & \\
\hline & final04_PURPOSE & \\
\hline & $\diamond$ SHAPE & \\
\hline & Label & \\
\hline & $\diamond$ SHAPE_Length & \\
\hline & SHAPE_Area & \\
\hline & Indexes & \\
\hline & + FDO_OBJECTID & \\
\hline & + FDO_SHAPE & \\
\hline & + I11final04_ORGAN & \\
\hline & + I11final04_COUNT & \\
\hline
\end{tabular}

\begin{tabular}{|l|}
\hline Continents \\
Feature Class \\
- Fields \\
OBJECTID \\
Shape \\
cONTINENT \\
SQMI \\
\hline SQKM \\
Iabel \\
Shape_Length \\
Shape_Area \\
Indexes \\
+ FDO_OBJECTID \\
+ FDO_Shape \\
\hline
\end{tabular}

\begin{tabular}{|c|c|}
\hline \multicolumn{2}{|c|}{$\begin{array}{l}\text { Donations2005 } \\
\text { Feature Class }\end{array}$} \\
\hline \multicolumn{2}{|c|}{ - Fields } \\
\hline & OBJECTID \\
\hline & final05_COUNTRY \\
\hline & $\checkmark$ final05_ORGANIZATI \\
\hline & Final05_MEDICAL_CO \\
\hline & $\vee$ final05_MED_EQUIPM \\
\hline & $\checkmark$ final05_OTHER \\
\hline & $\checkmark$ final05_PHARMACEUT \\
\hline & Final05_TOTAL \\
\hline & Final05_YEAR_ \\
\hline & final05_PURPOSE \\
\hline & $\checkmark$ SHAPE \\
\hline & Label \\
\hline & $\checkmark$ SHAPE_Length \\
\hline & $\checkmark$ SHAPE_Area \\
\hline - & Indexes \\
\hline & + FDO_OBJECTID \\
\hline & + FDO_SHAPE \\
\hline & + I10final05_ORGAN \\
\hline & + I10final05_COUNT \\
\hline
\end{tabular}

\begin{tabular}{|l|}
\hline Cntry00 \\
Feature Class \\
- Fields \\
OBJECTID \\
Shape \\
CNTRY_NAME \\
FIRST_FIRS \\
GDP2 \\
Shape_Length \\
Shape_Area \\
MemberCount_2006 \\
DonationTotal_2006 \\
- DonationTotalLabel_2006 \\
Indexes \\
+ FDO_OBJECTID \\
+ FDO_Shape \\
+ Name \\
+ + count
\end{tabular}

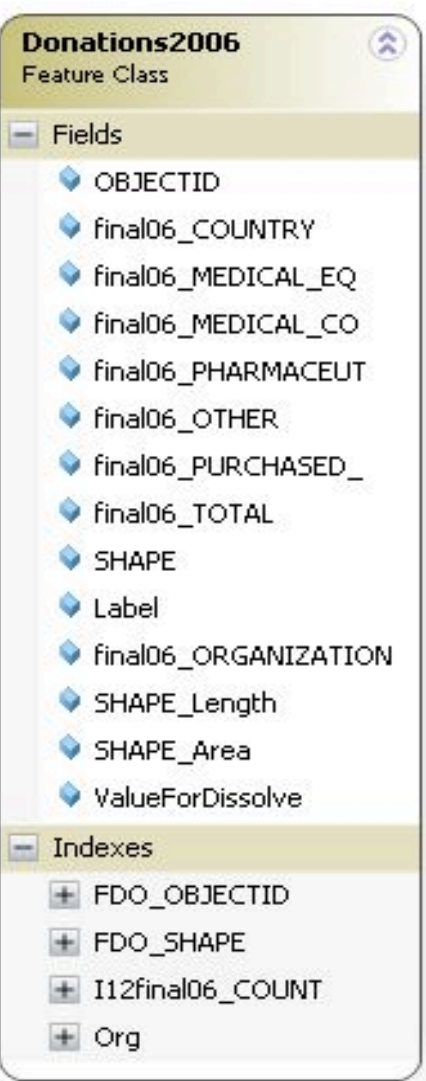

\begin{tabular}{|l|}
\hline WORLD30 \\
Feature Class \\
- Fields \\
OBJECTID \\
Shape \\
wRLD30_ID \\
\hline Label \\
Shape_Length \\
Shape_Area \\
- Indexes \\
+ FDO_OBJECTID \\
+ FDO_Shape \\
\hline
\end{tabular}

\section{Appendix Figure 1. PQMD OMS Geodatabase Diagram}





\section{Appendix B - Complete System via ArcCatalog}

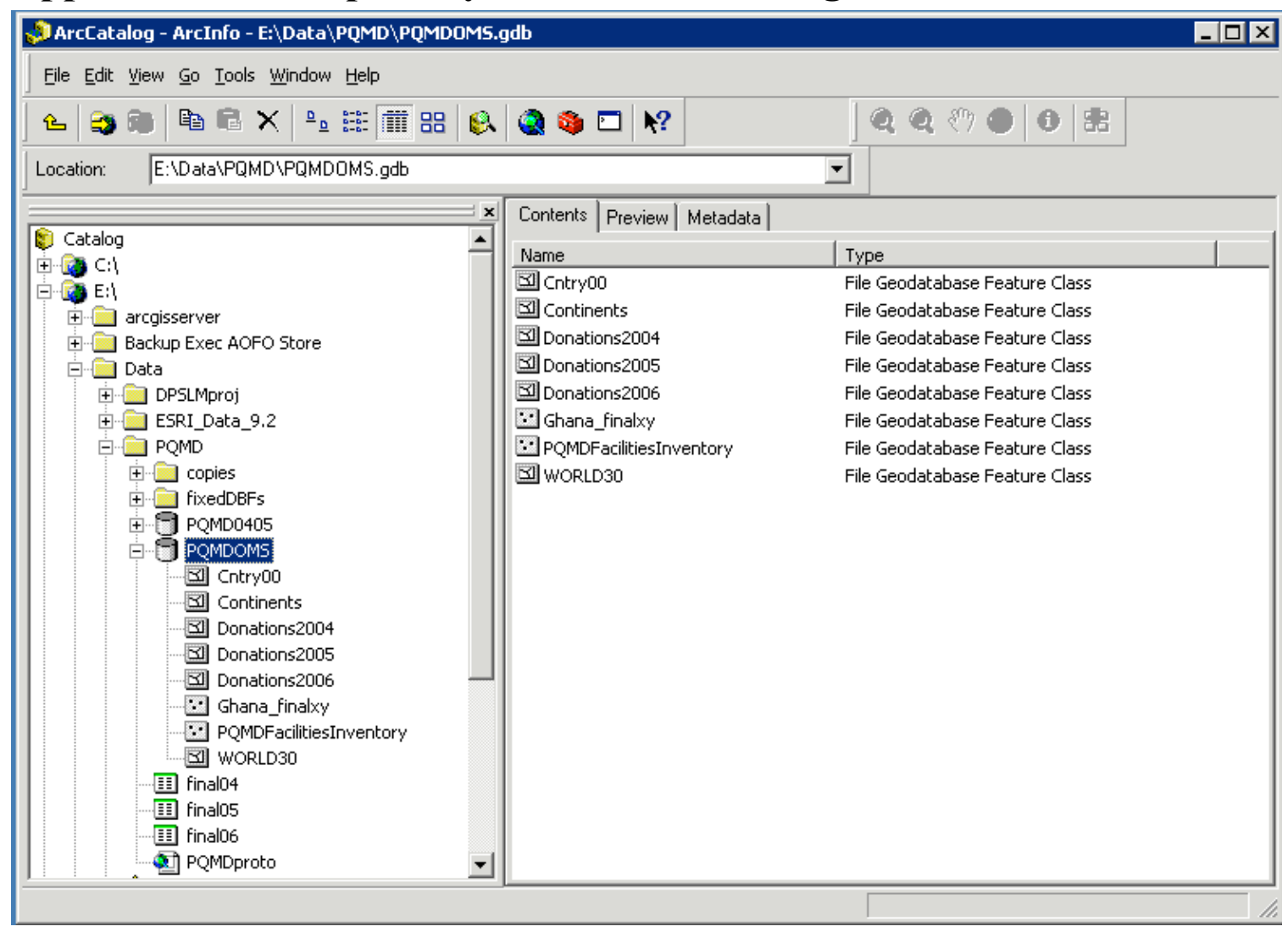

Appendix Figure 2. PQMD OMS System Files 